\title{
LA POLÍTICA EXTERIOR DEL GOBIERNO DE ENRIQUE PEÑA NIETO HACIA AMÉRICA LATINA Y EL CARIBE EN UN MUNDO EN TRANSICIÓN: UNA TRAMA EN TRES ACTOS
}

\author{
THE FOREIGN POLICY OF THE GOVERNMENT OF \\ ENRIQUE PEÑA NIETO TOWARDS LATIN AMERICA \\ AND THE CARIBBEAN IN A WORLD IN TRANSITION: \\ A DRAMA IN THREE ACTS
}

\section{LA POLITIQUE ÉTRANGÈRE DU GOUVERNEMENT D'ENRIQUE PEÑA NIETO POUR L'AMÉERIQUE LATINE ET LES CARAÏBES DANS UN MONDE EN TRANSITION: UNE PIĖGE EN TROIS ACTES}

\author{
Guadalupe GonZÁlez GonZÁlez \\ El Colegio de México \\ mgonzalez@colmex.mx \\ Rodrigo Morales Castillo \\ Secretaría de Relaciones Exteriores \\ rodrigo.morales.castillo@gmail.com
}

Resumen: Los responsables de tomar decisiones suelen formular, reestructurar, reformar o ajustar la política exterior mexicana hacia América Latina y el Caribe a partir de los cambios que se generan en los tableros a nivel internacional, regional y nacional. Al respecto, el sexenio del presidente Enrique Peña Nieto es un caso de estudio esclarecedor, ya que durante su gestión el gobierno mexicano tuvo que responder a varias coyunturas que se presentaron en estas tres pistas de acción, incluso de manera simultánea. De acuerdo con estas adaptaciones, a lo largo del periodo estudiado registramos tres ciclos de la diplomacia peñista en la región: promoción, repliegue y contención.

Palabras clave: política exterior; México; América Latina; Caribe; promoción; repliegue; contención; diplomacia. 
ABSTRACT: Those responsible for making decisions usually formulate, restructure, reform or adjust Mexican foreign policy towards Latin America and the Caribbean based on the changes that take place on the chessboard at the international, regional and national levels. In this regard, the presidency of President Enrique Peña Nieto is an illuminating case study, since during his administration the Mexican government had to respond to a number of situations that arose in these three fields of action simultaneously. In line with these adaptations, over the period studied we recorded three cycles of diplomacy by Peña in the region: promotion, withdrawal, and containment.

Keywords: foreign policy; Mexico; Latin America; Caribbean; promotion; withdrawal; containment; diplomacy.

\section{Traducción de Gonzalo Celorio Morayta}

Résumé: Les responsables de prendre des décisions ont l'habitude de formuler, de réorganiser, de réformer ou d'adapter la politique du Mexique vis-à-vis du reste de l'Amérique latine et des Caraibes en fonction des bouleversements qui se produisent sur le plan international, régional ou national. La période présidentielle d'Enrique Peña Nieto est révélatrice dans la mesure que le gouvernement mexicain a dû répondre à des changements sur les trois scènes, parfois simultanés. Durant cette période, l'adaptation de la diplomatie pour la région qui nous intéresse a traversé trois étapes: promotion, repli et contention.

Mots clefs: Mexique; Amérique latine; Caraïbes; promotion; repli; contention; diplomatie.

Traducción de BERNARDo Mabire

Fecha de recepción: diciembre de 2018

Fecha de aceptación: febrero de 2019 
L OS prismáticos analíticos con los que suele observarse a América Latina y el Caribe (ALyc) desde México no siempre enfocan con claridad la importancia estratégica, económica, política y social de la región para nuestro país. En la literatura académica, el reiterado desfase entre el interés simbólico y material de México en la región tiende a reducir el análisis a cuestiones de reputación y geopolítica. ${ }^{1}$ Este acercamiento resulta insuficiente para entender las razones detrás de los ostensibles cambios de atención y actividad diplomática de México, incluso dentro de una misma administración, en momentos más discreta y pragmática que vocal e ideológica. Esta distorsión usualmente se deriva de la escasa sistematización de las variables y contextos cambiantes que inciden en el comportamiento de la política exterior mexicana.

¿Cuáles son las fuerzas que mueven la atención y actividad diplomática mexicana en ALyc? Nuestro análisis se propone comprender la compleja interacción entre los escenarios internacional, regional y doméstico, y cómo cambios simultáneos en los tres niveles generan estímulos positivos y negativos que, desde la perspectiva de los responsables de tomar decisiones, exigen hacer ajustes para adaptar la política exterior a las condiciones resultantes.

La política exterior hacia ALyc ejecutada durante el sexenio de Enrique Peña Nieto (EPN) es un caso de estudio enriquecedor al respecto, ya que ilustra las motivaciones que condicionaron una mayor, aunque variable, atención y actividad diplomática en la región que la de los gobiernos panistas, en un contexto nacional, regional e internacional sumamente cambiante. Como una obra teatral de tres actos, la actuación diplomática tuvo una apertura, un interludio y un clímax final, mostrando, entre actos, la flexibilidad de ajuste para responder a las necesidades del

${ }^{1}$ Esta tesis, originalmente planteada por Daniel Cosío Villegas, es que "en América Latina los intereses de México son sobre todo sentimentales, o cuando más, de prestigio, es decir, lo que menos importa en la Realpolitik internacional". Véase Daniel Cosío Villegas, "Vida azarosa de la Doctrina Estrada”, en Problemas de América, México, Clío y El Colegio Nacional, 1997, p. 341. 
momento dentro de la gran trama de acercamiento pragmático hacia la región.

Además de la presente introducción y conclusiones, este artículo se compone de otras cuatro secciones. En la primera, se desarrolla el marco analítico utilizado para comprender cuáles fueron las fuerzas conductoras de la política exterior durante este sexenio y qué tan activa fue. En la segunda, se explican los mecanismos causales que configuraron la diplomacia de promoción en la apertura de la presidencia de Peña Nieto. En la tercera, se exponen los factores que motivaron la adaptación de la política inicial, reduciendo el activismo diplomático en ALyc, pero tornándola más vocal con respecto a las crisis regionales. Por último, en el cuarto segmento, se presentan las causas que originaron un ajuste mayor de la política exterior, reencendiendo los motores de la diplomacia regional mexicana y dando lugar a acciones inéditas como el activismo en la Organización de Estados Americanos (OEA) en torno a Venezuela o la vinculación instrumental de la política comercial con Argentina y Brasil durante las negociaciones del Tratado de Libre Comercio de América del Norte (TLCAN) que condujeron al Tratado México, Estados Unidos y Canadá (T-MEC).

Marco ANALítico: ¿QUÉ TANTO, Cómo Y POR QUÉ VARÍA EL NIVEL Y TIPO DE ATENCIÓN Y ACTIVIDAD DIPLOMÁTICA EN LA REGIÓN?

Estudios recientes en el campo de política exterior comparada en América Latina ${ }^{2}$ han encontrado que, en general, la

${ }^{2}$ Estos estudios centran el análisis empírico en los patrones de votación de los países latinoamericanos en la Asamblea General de Naciones Unidas. Véase: Octavio Amorim Neto y Andrés Malamud, "What determines foreign policy in Latin America? Systemic versus domestic factors in Argentina, Brazil, and Mexico", Latin American Politics and Society, vol. 57, núm. 4 (2015), pp. 1-27; y Federico Merke, Diego Reynoso y Luis Schenoni, "Foreign policy change in Latin America: exploring 
diplomacia mexicana ha sido más continua y estable desde el fin de la Guerra Fría que la de otros países grandes de la región (Argentina, Brasil y Venezuela). También argumentan que en México, al igual que en Chile, la política exterior ha sido menos sensible a los vaivenes de la política interna, la rotación de coaliciones en el poder e, incluso, al cambio de régimen y la democratización. Esta literatura abre preguntas clave con respecto a cómo abordar conceptual y empíricamente los patrones de estabilidad y cambio de la política exterior mexicana de manera sistemática y comparativa.

Aunque la orientación liberal y norteamericana de la política exterior mexicana, resultante de su última reestructuración (en términos de Lasagna) ${ }^{3}$ en los años noventa, no se ha visto alterada por las transformaciones sistémicas, turbulencias regionales y alternancias políticas desde entonces, sí han ocurrido reformas (modificaciones lentas, incrementales y parciales) y ajustes (alteraciones adaptativas) en los patrones de política exterior. Son los cambios no radicales, incrementales y adaptativos los que nos interesa examinar.

Además del registro de la política sexenal, ¿cuál es la relevancia analítica de investigar este tipo de modificaciones? Existen tres razones: ${ }^{4}$ la primera es desarrollar indicadores

a middle-range concept", Latin American Research Review, (2020, en prensa), pp. 1-33.

${ }^{3}$ Lasagna distingue tres tipos de cambios: reestructuración, reforma y ajuste. La reestructuración se refiere a una modificación rápida y radical de los fundamentos de política exterior. Véase: Marcelo Lasagna, "Las determinantes internas de la política exterior. Un tema descuidado en la teoría de la política exterior”, Estudios Internacionales, 28, núm. 111 (1995), p. 402; y Marcelo Lasagna, "Cambio institucional y política exterior: un modelo explicativo", Afers Internacionals, núm. 32 (1996), pp. $45-64$.

${ }^{4}$ Sobre el debate académico en torno a esta agenda de investigación, Véase: Jakob Gustavsson, "How should we study foreign policy change?", Cooperation and Conflict, vol. 34, núm. 1 (1999), pp. 73-95; Charles Hermann, "Changing Course: When governments choose to redirect foreign policy”, International Studies Quarterly, vol. 34, núm. 1 (1990), pp. 3-21; y Alba E. Gámez, "Fuentes de cambio en política exterior. Una revisión de 
cuantitativos y replicables, que permitan identificar variaciones de atención y actividad diplomática de manera más precisa que la tipología categórica de política exterior (pasiva, reactiva y proactiva). Segunda, explorar cómo operan e interactúan, en coyunturas específicas, los mecanismos a nivel sistémico, regional y doméstico ${ }^{5}$ que impulsan o inhiben la acción diplomática y qué tipo de efecto motivacional ejercen sobre quienes toman decisiones. Por último nos interesa indagar sobre el papel de los cancilleres, su nivel de actividad y estilo diplomático ${ }^{6}$ (ideológico o pragmático) ${ }^{7}$ como unidad decisoria complementaria del liderazgo presidencial. ${ }^{8}$

A continuación, se especifican los elementos analíticos (variables, etapas y mecanismos causales) sobre los que sustentamos el argumento de que la política latinoamericana y caribeña de México durante el sexenio de EPN no significó una ruptura respecto del gobierno anterior, sino un intento de reactivación pragmática en tres etapas de ajustes que respondieron a coyunturas críticas debido a cambios globales, regionales y nacionales.

Nuestra variable dependiente son los patrones de cambio y continuidad en el nivel y tipo de atención y actividad diplo-

los modelos de política exterior para los países en desarrollo", Afers Internacionals, núm. 69 (2005), pp. 127-151.

${ }^{5}$ Rita Giacalone, "Latin American foreign policy analysis: external influences and internal circumstances", Foreign Policy Analysis, vol. 8, núm. 4 (2012), pp. 335-354.

${ }^{6}$ Merke y Reynoso distinguen cuatro dimensiones de política exterior con fines comparativos: estilo diplomático (ideológico o pragmático), orientación geopolítica (sur o norte), orientación económica (proteccionismo o apertura) y orientación hacia Estados Unidos (autonomía o alineamiento). Véase: Federico Merke y Diego Reynoso, "Dimensiones de política exterior en América Latina según juicios de expertos", Estudios Internacionales, 185 (2016), pp. 107-131.

${ }^{7}$ Gianluca Gardini y Paul Lambert, Latin American foreign policies: between ideology and pragmatism, Londres, Palgrave Macmillan, 2011, 272 pp.

${ }^{8}$ Andrés Malamud, "Presidentialist decision making in Latin American foreign policy: examples from regional integration processes", en Jorge Domínguez y Ana Covarrubias (eds.), Routledge Handbook of Latin America in the World, Londres, Routledge, 2014, pp. 112-123. 
mática desplegada por el gobierno mexicano en ALyc. Las variables explicativas se ubican en la interacción entre tres niveles de análisis (gráfica 1) a lo largo del periodo y determinan coyunturas críticas: a) sistémicas (la política exterior de Estados Unidos, la situación económica mundial y el papel de actores extrarregionales); b) regionales (cambios de gobierno, crisis por inestabilidad política, desastres, migración y violencia, entre otros, y crecimiento económico); y, c) domésticas (apoyo presidencial, base política, crisis por inseguridad y corrupción y ciclo electoral).

Para medir los cambios, desarrollamos un índice de atención y actividad diplomática que permite hacer comparaciones sistemáticas entre las gestiones de los tres cancilleres que tuvo la administración de EPN. Este índice estima la tasa promedio de actividad diaria registrada durante el periodo de cada canciller. El resultado es la suma de las giras presidenciales y de cancilleres a la región, más los encuentros diplomáticos ${ }^{9}$ sostenidos por México con los países de ALyc entre el total de días en que cada canciller se mantuvo en el cargo. Por último, para medir el grado de atención, se desarrollaron tres subíndices de acuerdo con el nivel o tipo de contacto: presidencial, de cancilleres y de alto nivel.

Con base en la evolución de este índice identificamos tres momentos distintos en la política exterior latinoamericana y caribeña de la administración peñista: promoción (del $1^{\circ}$ de diciembre de 2012 al 27 de agosto de 2015) con el nivel más alto de actividad diplomática y atención presidencial del sexenio; repliegue (del 28 de agosto de 2015 al 3 de enero de 2017) con los niveles más bajos de actividad, pero con atención tan-

${ }^{9}$ Entre el $1^{\circ}$ de diciembre de 2012 y el 31 de agosto de 2018 , el presidente Peña Nieto realizó 40 visitas a quince países latinoamericanos y caribeños; de éstos, los de la AP fueron los más visitados: Colombia (8), Perú (6) y Chile (4). Por su parte, los cancilleres efectuaron 117 giras a 27 países de la región; y, durante los 69 meses que abarca este análisis, contabilizamos un total de 409 encuentros de alto nivel con 29 países de ALyc. Solamente no se obtuvo registro con Antigua y Barbuda, Granada y San Cristóbal y Nieves. 


\section{GrÁFICA 1}

Niveles de análisis de la política exterior de México hacia ALyc durante el sexenio de EPN

\section{Promoción}

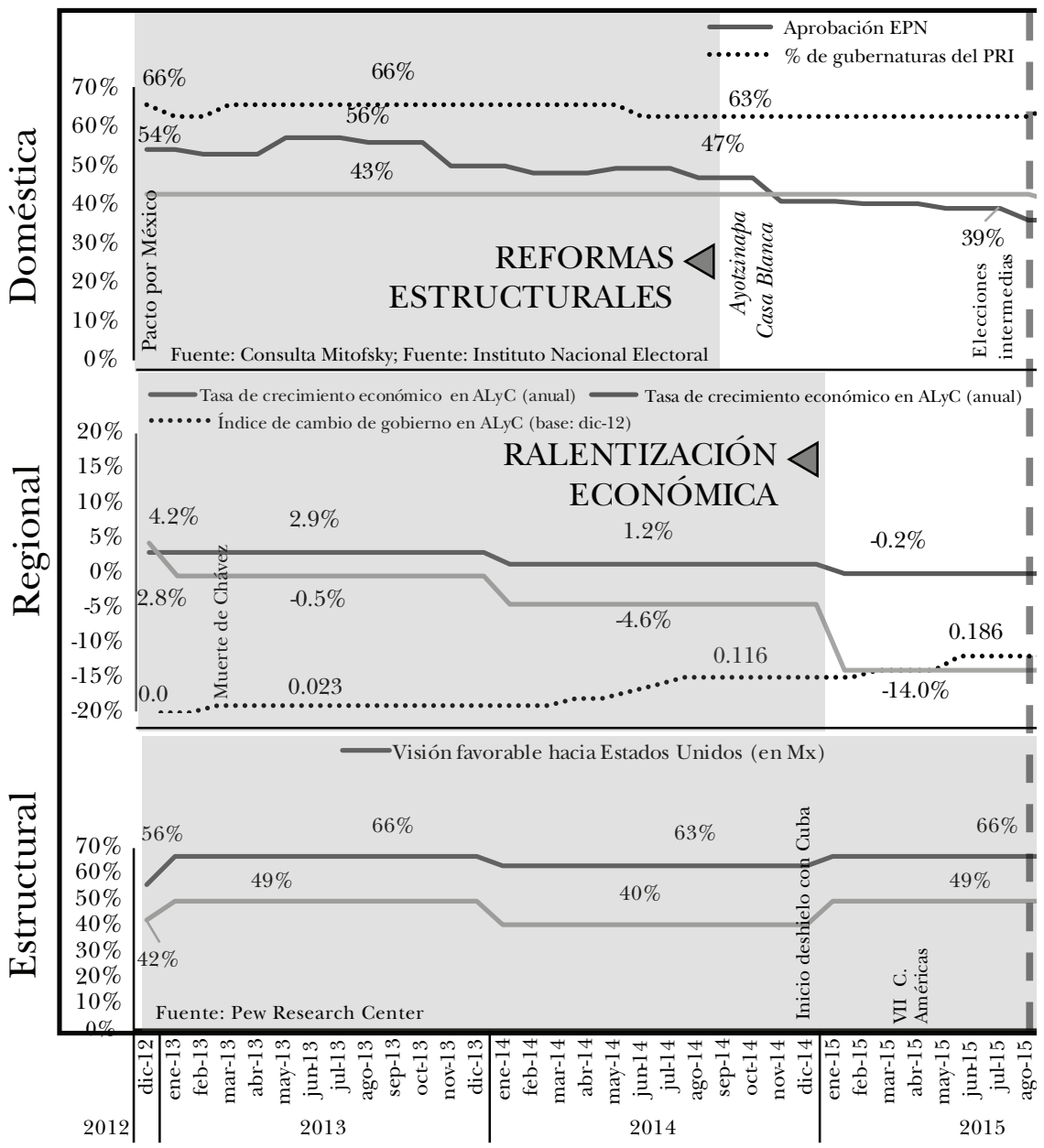

Fuente: Consulta Mitofsky; porcentaje del PRI en el Congreso, fuente: Instituto Nacional Electoral; porcentaje de gubernaturas del PRI, fuente: Instituto Nacional Electoral. Regional: Tasa de crecimiento económico en Alyc (anual), fuente: CEPAL; Tasa de crecimiento comercial México-Alyc (anual), fuente: Secre- 


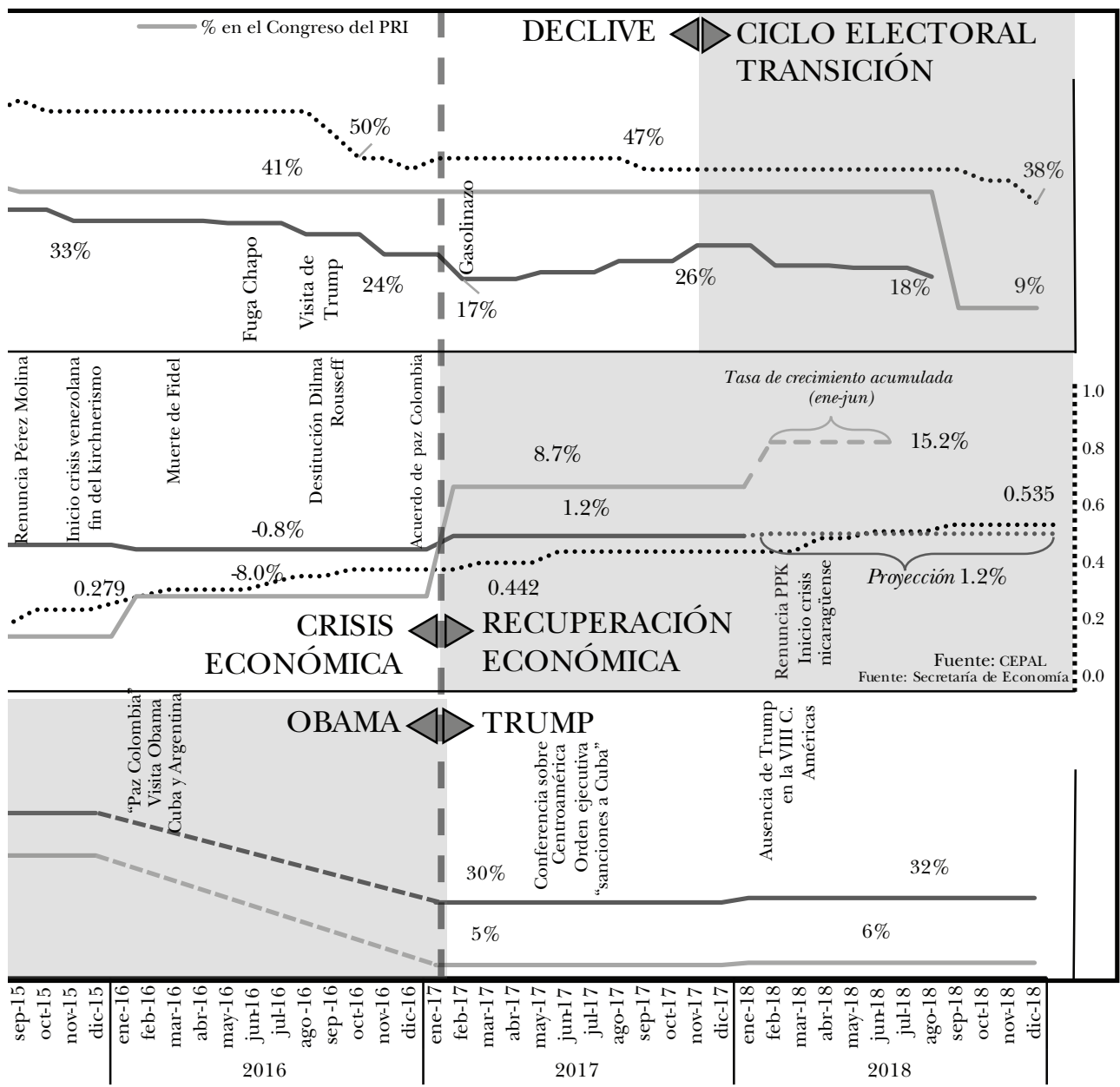

taría de Economía; Índice de cambio de gobierno en Alyc (base diciembre de 2012), fuente: The Database of Political Institutions 2017/KnowledgeWalk Institute. Estructural: Visión favorable hacia Estados Unidos (en México), fuente: Pew Research Center; confianza en el presidente de Estados Unidos (en México), fuente: Pew Research Center. 
to presidencial como de canciller y ministerial; y contención (del 4 de enero de 2017 al 31 de agosto de 2018) ${ }^{10}$ en el que se recupera el nivel de actividad, pero baja la atención presidencial mientras sube notablemente el dinamismo del canciller (gráfica 2).

GrÁfICA 2

Índice de actividad

( $1^{\circ}$ de diciembre de 2012 a 31 de agosto de 2018)

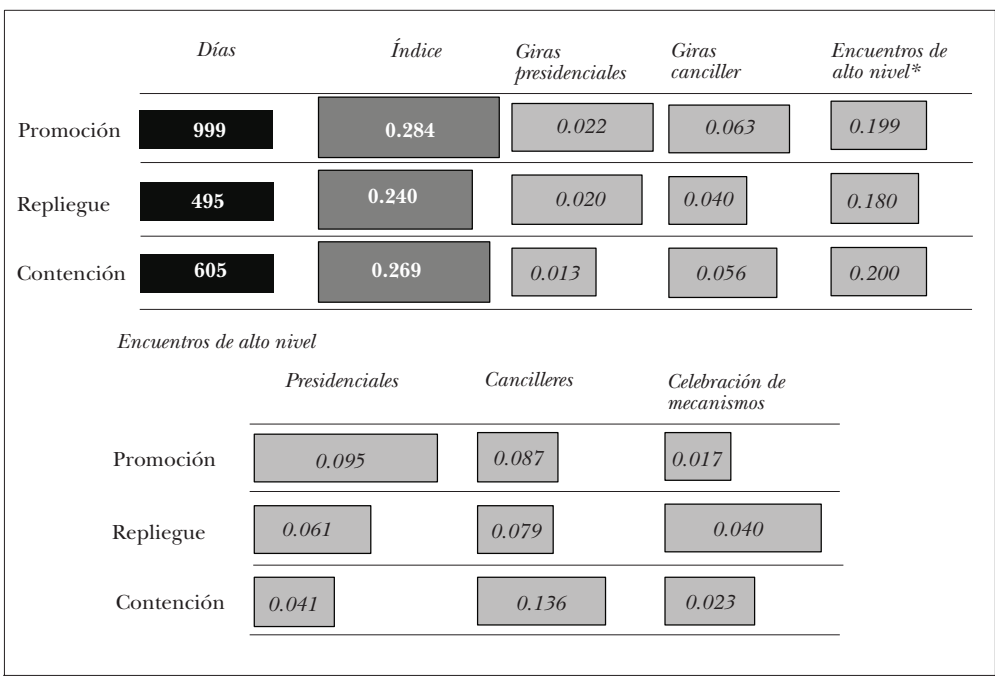

* Incluye encuentros presidenciales, de cancilleres y celebración de mecanismos con un nivel mínimo de viceministro.

Fuente: elaboración propia con información de la Secretaría de Relaciones Exteriores.

Estas etapas corresponden a los periodos de gestión de los tres cancilleres que ocuparon la titularidad de la Secretaría de Relaciones Exteriores (SRE), lo que sugiere que los cambios,

${ }^{10}$ Debido a los tiempos editoriales, los últimos tres meses del sexenio de EPN quedaron fuera de los cálculos finales. 
ajustes y perfiles de los secretarios en turno fueron resultado del cálculo del presidente frente a las cambiantes condiciones internacionales, regionales y nacionales: el primer movimiento del titular respondió a factores de orden interno (agosto de 2015), mientras que el segundo (enero de 2017) obedeció al giro radical desatado por el fenómeno Trump.

Por último, distinguimos cinco mecanismos causales detrás de la atención y actividad diplomática de México en la región, dependiendo del nivel donde se detona la acción: el estratégico que se activa en función de la relación con Estados Unidos y de otros actores extrarregionales por cálculos para equilibrar o ampliar los márgenes de maniobra o para contener, apaciguar y acomodar las demandas del vecino del norte; el mecanismo de proyección que opera de adentro hacia afuera para promover intereses económicos, políticos y simbólicos en torno a una narrativa global; el de arrastre, que se activa como bola de nieve por turbulencias y crisis regionales que evolucionan de manera imprevista; el interno, resultado del juego y del cálculo político doméstico y de las características del proceso de toma de decisiones y, por último, el inercial/protocolario, que reproduce patrones de acción institucionalizados por acuerdos previos o estándares burocráticos.

\section{Promoción: AUGE Y CAÍdA DEL "MOMENTO MEXICANO"}

En los albores del sexenio, la administración del presidente Peña Nieto desplegó una activa política de comunicación social enfocada en fortalecer la percepción de que una nueva era había iniciado en México. El "nuevo PRI" -que simbolizó el mea culpa del priismo y el cambio generacional de sus líderes- desarrolló una potente narrativa en torno a los consensos alcanzados con el Pacto por México: tras 12 años de bloqueo político, el gobierno peñista logró aprobar once reformas estructurales para impulsar la competitividad del país. La promoción internacional del proyecto reformista del presidente, sintetizada de manera elocuente por las publicacio- 
nes Time y The Economist, ${ }^{11}$ tenían por fin eclipsar los graves problemas nacionales de seguridad, al tiempo de cultivar una imagen positiva de México como economía emergente, estable y competitiva que brindaba nuevas y amplias oportunidades de inversión, negocios, comercio y turismo.

Esta narrativa encontró en Alyc un espacio natural e idóneo ${ }^{12}$ para la proyección internacional del nuevo gobierno, donde la agenda de competitividad nacional fue el principio ordenador de las tareas diplomáticas mexicanas en la región durante el periodo que denominamos como de promoción. El Plan Nacional de Desarrollo 2013-2018 (PND) estableció que "la integración comercial con América Latina" sería "una prioridad" dado que México, "con su red de acuerdos comerciales", tenía la oportunidad de "servir de plataforma logística y de negocios entre el norte y el sur del continente" y lograr que los esfuerzos de integración y desarrollo "no queden en el tintero". ${ }^{13}$

Por otra parte, en los inicios de la administración peñista, la variable estadounidense se mantuvo estable y caracterizada por la cordialidad e institucionalidad de la relación, anulando la utilidad de Alyc como instrumento de equilibrio frente a su vecino del norte. La visita realizada por Peña Nieto a Washington (noviembre de 2012) como presidente electo y la recíproca de Obama (mayo de 2013) lograron sentar las

11 El gran optimismo con el que los medios internacionales recibieron la agenda reformista se plasmó en varias portadas. Véase: "The rise of Mexico", The Economist, 24 de noviembre de 2012; "Mexico's moment", The Economist, 21 de noviembre de 2012; Michael Crowley, "The committee to save Mexico", Time, 24 de febrero de 2014; y Shannon K. O’Neil, "Mexico makes it a transformed society, economy, society, government", Foreign Affairs, vol. 92, núm. 2 (2013), pp. 52-63.

${ }^{12}$ El Plan Nacional de Desarrollo definió a la región como "el principal espacio de influencia geopolítica de México”, y a México como "«una pieza angular» de la estabilidad y la prosperidad regional”. Véase: Gobierno de la República, Plan Nacional de Desarrollo, 2013-2018, México, 2013, p. 93 .

13 Además de ser la región con mayor inversión mexicana (82 mmd en 2012), Loc. cit., p. 94. 
bases para capitalizar ese "momento mexicano" y relanzar la relación bilateral con el propósito de "desecuritizar" la agenda con asuntos económicos y de cooperación. En esta etapa, el factor estadounidense no tuvo un papel central en las acciones mexicanas hacia la región, salvo en temas migratorios y de seguridad fronteriza por situaciones de emergencia, como la detención por parte de Estados Unidos de cerca de 68000 menores centroamericanos indocumentados no acompañados en 2014, que llevó a México a adoptar medidas de contención migratoria (Programa Frontera Sur) y cooperación regional (Plan de Alianza para la Prosperidad del Triángulo del Norte de Centroamérica) con implicaciones en las relaciones con sus vecinos del sur. ${ }^{14}$

En el ciclo de promoción, la región no ejerció una fuerza centrípeta determinante sobre el comportamiento de la política exterior mexicana. Si bien empezaron a brotar algunos signos de inestabilidad, como la ralentización de la economía regional, ${ }^{15}$ no fue hasta el segundo semestre de 2015 que se acentuaron las crisis políticas, económicas y sociales, cuyas ramificaciones se sintieron hasta el fin del sexenio. Durante esta etapa, los cambios de gobiernos en los países latinoamericanos y caribeños, mediante elecciones o interrupciones de mandato, no generaron inestabilidad política. El ritmo promedio de variación fue de un nuevo gobierno cada cuatro meses (todos por la vía electoral), mientras que en la etapa de

${ }^{14}$ Daniel Villafuerte Solís y María del Carmen García Aguilar, "De la crisis de los niños migrantes a la crisis de la migración cubana: intereses geopolíticos y expresiones sociales de la crisis del sistema migratorio México-Estados Unidos-Centroamérica entre 2014-2015”, Boletín de Antropología, vol. 31, núm. 52 (2016), pp. 15-33.

${ }^{15}$ En 2012, el crecimiento económico registra un cambio de tendencia a la baja (de $4.5 \%$ en 2011 a $2.8 \%$ ) tras dos años de recuperación de la crisis de 2008-2009. La desaceleración continuó hasta 2016 (-1.0\%) con un ligero repunte en 2017 (1.3\%) y 2018 (1.2\%). Estudio Económico de América Latina y el Caribe 2018, Santiago de Chile, 2018, p. 205, https:/ repositorio.cepal.org/bitstream/handle/11362/43964/141/S1800837_ es.pdf (consulta del 2 de diciembre de 2018). 
repliegue fue de uno cada dos (seis alternancias electorales, una dimisión y una destitución del ejecutivo), y en la de contención, de uno cada tres (seis a través de las urnas y una renuncia presidencial). ${ }^{16}$

La muerte de Hugo Chávez (marzo de 2013) y la sucesiva elección democrática de Nicolás Maduro por la estrecha diferencia de 140000 votos, así como el inicio de la investigación judicial de Lava Jato en Brasil y la normalización institucional de Paraguay (tras la destitución de Fernando Lugo en junio de 2012) fueron los acontecimientos más relevantes, sin que le generaran a México urgentes demandas de atención durante esta etapa.

De esta forma, las necesidades de proyección internacional del "nuevo PRI", junto con las dinámicas internas que propiciaron un menor énfasis en la promoción de los derechos humanos y la democracia, herencia de los gobiernos panistas, fueron las fuerzas conductoras de la política exterior hacia Alyc en esta primera fase del gobierno. La diplomacia mexicana también contó con vientos favorables a la proyección económica por el inicio del declive de la "marea rosa" liderada por Argentina, Brasil y Venezuela que, durante la primera década del siglo xxi, produjo alineamientos regionales en torno a la Alianza Bolivariana de los Pueblos de Nuestra América (ALBA) y la Unión de Naciones Suramericanas (UNASUR), obstaculizando la presencia de México y ahondando su aislamiento relativo. ${ }^{17}$

A pesar del cambio de partido en el poder, el gobierno de EPN no buscó una reestructuración de la política latinoamericana de su antecesor sino, por el contrario, su continuación y

${ }^{16}$ Cálculos propios con datos de KnowledgeWalk Institute; Caribbean Elections, Election Centre (sitio de internet), última modificación, diciembre 2018, http:/ /www.caribbeanelections.com/elections/default. asp; Carlos Scartascini, Cesi Cruz y Philip Keefer, The database of political institutions 2017 (DPI2017), Washington, Banco Interamericano de Desarrollo, febrero de 2018.

17 Ana Covarrubias, "El reacomodo de México en una América Latina cambiante: de la euforia democrática a la introversión”, Pensamiento propio, vol. 21, núm. 44 (2016), pp. 325-326. 
profundización a través de un creciente activismo diplomático, aunque con mayor pragmatismo, nuevos énfasis subregionales (el Caribe, además de Centroamérica y el Pacífico latinoamericano) y renovados instrumentos (cooperación y alianzas estratégicas, además de acuerdos comerciales). La señal inicial de acercamiento e interés fue la decisión, como presidente electo, de realizar su primera gira internacional a ALyc, con su asistencia a la I Cumbre de la cELAC, en Santiago de Chile, seguida de una visita oficial a Uruguay (enero de 2013).

Durante la gestión del canciller José Antonio Meade, se suministró una alta dosis de activismo diplomático a Alyc. Medido de manera empírica, en términos absolutos (cuadro 1) y relativos (gráfica 2), la diplomacia a nivel presidencial y de cancillería registraron un mayor nivel de actividad en este periodo, en comparación con los dos posteriores: el presidente Peña Nieto realizó 22 visitas y sostuvo 95 encuentros con mandatarios latinoamericanos y caribeños, mientras que redujo la marcha a dieciocho viajes durante el repliegue y la contención y a 30 y 25 reuniones celebradas, respectivamente. Por su parte, el canciller Meade efectuó 63 giras en la región y 87 reuniones con sus pares. En contraste, los cancilleres Ruiz Massieu y Videgaray se trasladaron en 20 y 34 ocasiones y mantuvieron entre 39 y 82 entrevistas, respectivamente.

Bajo esta racionalidad de proyección, la diplomacia mexicana en ALyc siguió tres líneas de acción: promoción e impulso económico, construcción de un liderazgo basado en la "responsabilidad global" de México y normalización de relaciones diplomáticas con aquellos gobiernos con los que se distanciaron las administraciones de Fox y Calderón. En la dimensión bilateral se plantearon como objetivos: revertir la "inercia" competitiva con Argentina y Brasil, relanzar la relación con Cuba y restablecer la confianza con otros países del ALBA, así como profundizar las buenas relaciones con el Pacífico latinoamericano y Uruguay. ${ }^{18}$

18 Luis Alfonso de Alba, "La política exterior de México hacia América Latina y el Caribe 2012-2018, logros y prospectiva”, Revista 


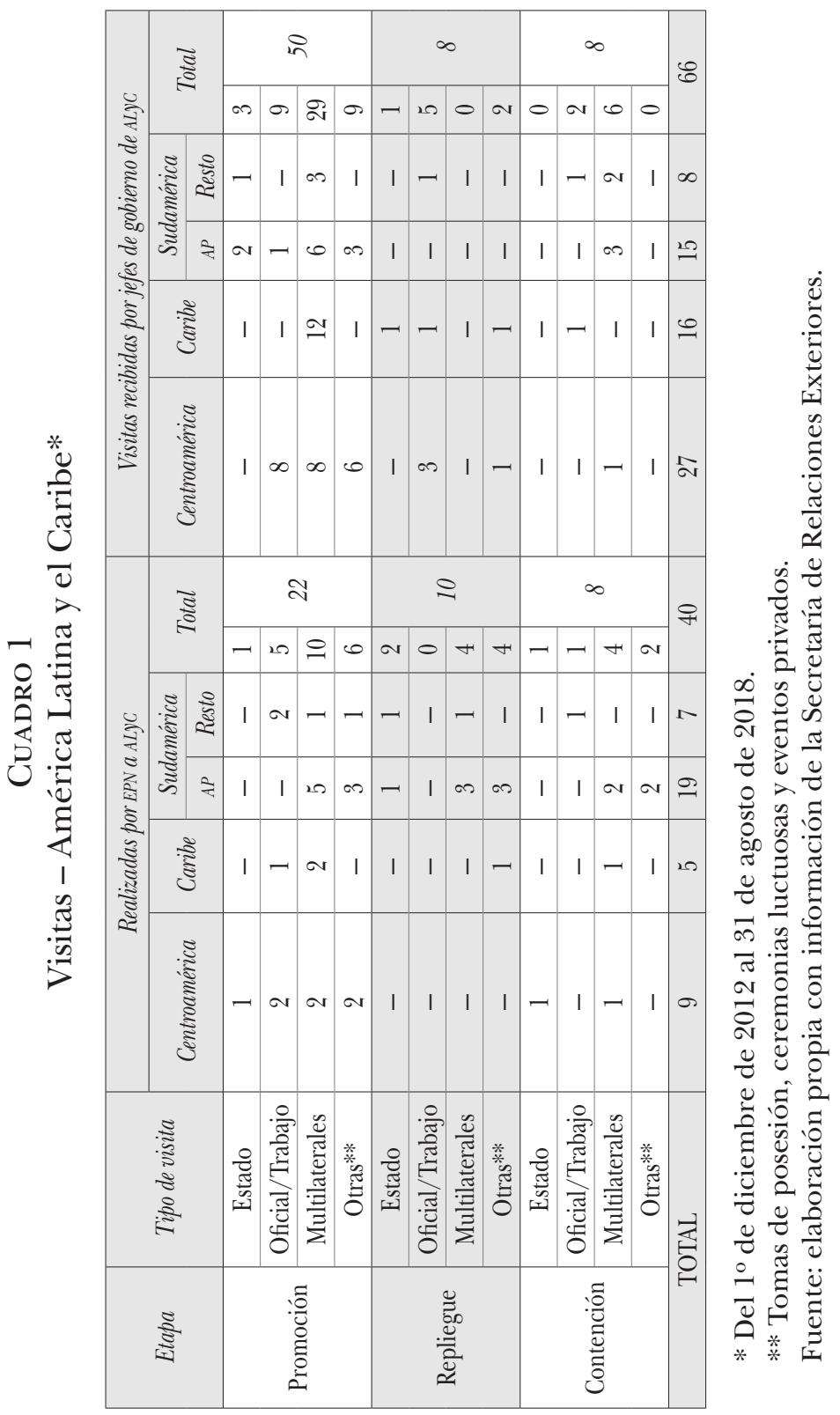


A diferencia de otros mecanismos heredados de la administración calderonista, como la CELAC, la Alianza del Pacífico (AP) fue la punta de lanza del gobierno de Peña Nieto en su proyección hacia ALyc al impulsar un modelo de "integración profunda" 19 más allá del libre comercio y alternativo a los esquemas latinoamericanos poshegemónicos. Con un inédito impulso a la integración de sus economías, los gobiernos de la AP lograron acuerdos rápidos y concretos con la eliminación de obstáculos a la circulación de bienes y servicios (liberalización arancelaria de 92\%), capitales (integración de mercados bursátiles) y personas (eliminación de visados), así como de cooperación (establecimiento de plataforma académica).$^{20}$ Este esquema de regionalismo abierto, a pesar de sus limitaciones en términos de comercio intrarregional, pronto acaparó la atención internacional al pasar de tres a 42 Estados observadores en este periodo ( 55 observadores a agosto de 2018).

Si bien la AP es un organismo esencialmente económico, el sustrato ideológico-político de democracias representativas también fue un elemento que el gobierno peñista buscó resaltar como parte de la identidad compartida de estos países como contrapeso a los regionalismos poshegemónicos. ${ }^{21}$ La prioridad que otorgó la administración a sus vínculos con estas naciones quedó de manifiesto durante la visita oficial de Ollanta Humala (julio de 2014) y las visitas de Estado realizadas por Juan Manuel Santos (mayo de 2015) y Michelle

Mexicana de Política Exterior, núm. 114 (septiembre-diciembre de 2018), p. 22.

${ }^{19}$ Según el PND, la integración comercial con América Latina va más allá de "la profundización de los acuerdos o a la negociación de nuevos instrumentos comerciales" e "incluye la convergencia de los tratados existentes", Gobierno de México, op. cit., p. 94.

${ }^{20}$ Eduardo Pastrana, La Alianza del Pacífico: de cara a los proyectos regionales y las transformaciones globales, México, Konrad Adenauer Stiftung / Gedisa /Pontificia Universidad Javeriana, 2016, 74 pp.

21 Natalia Saltalamacchia, "The Mexican agenda in Latin America: The Pacific Alliance”, CRIES, Anuario de la integración regional de América Latina y el gran Caribe, núm. 10, 2014, p. 154. 
Bachelet (agosto de 2015) a México, ocasiones en las que se elevó la relación a asociación estratégica con Perú y Colombia, y se reforzó la que ya se tenía con Chile desde 2007.

A través de la AP, la agenda bilateral ganó densidad con estos socios estratégicos, facilitando consultas y posicionamiento conjuntos en temas regionales (como la situación venezolana) e internacionales (como la protección del libre comercio y la lucha contra las drogas). Además, el presidente mexicano buscó, de manera simbólica, refrendar esa importancia al asistir a todas las tomas de posesión de sus pares de la AP, las únicas que efectuó durante su sexenio. ${ }^{22}$ No obstante, el acercamiento de México con el Pacífico latinoamericano tuvo alcances acotados. México, a diferencia de Chile, no tuvo ningún rol activo en el acompañamiento internacional de los diálogos de paz con las Fuerzas Armadas Revolucionarias de Colombia (FARC) que iniciaron en 2012. El involucramiento mexicano vino más tarde, con expresiones de apoyo al proceso en 2015 y, en 2016, como parte de la Misión de Verificación del Acuerdo de Paz de Naciones Unidas.

Otros indicadores de promoción económica fueron la entrada en vigor del Tratado de Libre Comercio Único con Centroamérica (2013) y la adopción de otro con Panamá (2015). Pero de particular relevancia, y como corolario de la ralentización económica regional, fue el creciente interés de países sudamericanos en la modernización y profundización de sus respectivos acuerdos económicos con México. En ese sentido, la visita de Estado que realizó Dilma Rousseff (mayo de 2015) marcó un hito en el distanciamiento relativo entre los gigantes latinoamericanos, al sentar las bases de entendimiento para renegociar sus vínculos económicos. El pragmatismo económico de la diplomacia peñista diluyó la actitud de rivalidad y competencia con Brasil de las dos administra-

22 Michelle Bachelet (marzo de 2014), Juan Manuel Santos (agosto de 2014), Pedro Pablo Kuczynski (julio de 2016), Sebastián Piñera (marzo de 2018) e Iván Duque (agosto de 2018). 
ciones panistas. ${ }^{23}$ En los momentos posteriores del sexenio, esta buena sintonía trascendió a otros aspectos bilaterales (cooperación y narcotráfico) y mejoró la colaboración en foros regionales (oEA y Grupo de Lima) y globales (G20), algo impensable un lustro previo.

"México, actor con responsabilidad global" fue un segundo elemento articulador del relato del "nuevo PRI" en ALyC, ${ }^{24}$ que llevó a potenciar la cooperación para el desarrollo como instrumento de acercamiento, atención y compromiso con Centroamérica y el Caribe, subregiones destino de más de $60 \%$ de las acciones directas de cooperación de México. ${ }^{25} \mathrm{~A}$ través de la Agencia Mexicana de Cooperación Internacional para el Desarrollo (Amexcid) y el programa Mesoamérica, el gobierno mexicano asumió un papel proactivo en esquemas bilaterales, triangulares y multilaterales al otorgar becas, financiar cooperación técnica, enviar ayuda humanitaria y responder a desastres naturales. Destacan la cooperación financiera a través del Fondo Yucatán para el desarrollo de infraestructura y la condonación de la deuda cubana por parte de Bancomext.

Asimismo, como parte de los esfuerzos de relaciones públicas se buscó dar visibilidad global al gobierno peñista a tra-

${ }^{23}$ Covarrubias describe la respuesta mexicana frente a la emergencia de Brasil como una mezcla de acercamiento, contención y evitar quedar fuera de iniciativas regionales. Ana Covarrubias, "Containing Brazil: Mexico's response to the rise of Brazil", Bulletin of Latin American Research, vol. 35, núm. 1 (2015), p. 49.

${ }^{24}$ El PND y el Plan Sectorial de Relaciones Exteriores vinculan explícitamente las iniciativas regionales en ALyc a la estrategia de proyección global. Según el PND, si México quiere "ser un nuevo actor global, lo primero que tiene que hacer es ser importante en su vecindario, es decir, ser líder a nivel regional. Quien no es líder en su región no es tan relevante a nivel global". Gobierno de la República, op. cit., p. 98.

${ }^{25}$ El objetivo era "atender las causas" de la inseguridad, la emigración y la falta de desarrollo con el principio de "responsabilidad compartida". Miguel Díaz Reynoso, "Política exterior de México hacia Centroamérica y el Caribe", Revista Mexicana de Política Exterior, núm. 114 (septiembre-diciembre de 2018), p. 42. 
vés de la celebración de cumbres internacionales (cuatro de los cinco encuentros hospedados por México durante el sexenio se realizaron en esta etapa). Con la finalidad de proyectar una imagen de "liderazgo solidario y responsable" se intentó construir un espacio propio de influencia en el Caribe mediante las giras del canciller Meade (siete viajes contra dos de Ruiz Massieu y tres de Videgaray) y la celebración de la VI Cumbre de la Asociación de Estados Caribeños (AEC) y la III Cumbre México-CARICOM (ambas en abril de 2014 en Mérida), donde México se comprometió a establecer programas de cooperación en caso de desastres naturales y comercio. Una motivación adicional explícita fue apuntalar el afán por ganar presencia y candidaturas multilaterales, para lo cual el respaldo caribeño era vital. ${ }^{26}$

Además, con la realización de la XXIV Cumbre Iberoamericana (diciembre de 2014 en Veracruz), un mecanismo añejo de la diplomacia mexicana que no se celebraba en el país desde su fundación en 1991, se intentó apoyar la proyección de México como actor global responsable. Sin embargo, en el contexto nacional en el que se realizó la cumbre por los casos de Tlatlaya y Ayotzinapa, este protagonismo se desdibujó en un encuentro protocolario con un retorno político pobre para el gobierno.

Un último vector de la política latinoamericana de México durante este tramo del sexenio respondió a las necesidades internas del "nuevo PRI" de ganar legitimidad entre la izquierda mexicana. Debido a la disociación de AMLO del Pacto por México, la izquierda partidista se fragmentó, generando presiones hacia el gobierno de EPN para confeccionar políticas que lo legitimaran frente a los sectores con reservas. Con este fin, la administración priista descafeinó el multilateralismo liberal de promoción de la democracia y derechos humanos, eje rector de la diplomacia regional del panismo que había provocado el distanciamiento con Cuba

${ }^{26}$ Secretaría de Relaciones Exteriores, Primer Informe de Labores 2012 2013, México, sRe, 2013, p. 16. 
y Venezuela. El renovado activismo peñista en ALyc hizo caso omiso de las diferencias político-ideológicas a fin de limar asperezas y buscar un acercamiento pragmático en temas comerciales, financieros, infraestructura y cooperación técnica, educativa y cultural.

Tras los exabruptos del foxismo, el intento de Felipe Calderón de recomponer la relación con Cuba no logró eliminar las diferencias de fondo en materia de derechos humanos. En este contexto heredado, la administración peñista buscó relanzar la relación bilateral por tres motivos posibles: además de los intereses internos de legitimación y deslindamiento del panismo, Cuba era una pieza ineludible para concertar acciones y fortalecer iniciativas regionales debido a su influencia entre los gobiernos de izquierda latinoamericanos y caribeños y, por último, un mercado potencial de comercio e inversión a la luz de las reformas económicas en la isla. ${ }^{27} \mathrm{El}$ giro comercial y financiero del acercamiento con Cuba fue un elemento novedoso en la diplomacia mexicana. Posteriormente, el deshielo entre Estados Unidos y Cuba generó un clima que favoreció la participación del empresariado mexicano en el proceso de actualización del modelo cubano.

Esas directrices nutrieron una diplomacia hacia la isla notablemente activa durante la gestión del canciller Meade, que sentó las bases de un nuevo entendimiento y una buena sintonía que duró hasta el fin del sexenio. El arranque con Cuba fue destacadamente dinámico: los 16 encuentros de alto nivel en este periodo (0.016 relativo), donde destaca la visita oficial de Peña Nieto a La Habana (enero de 2014) contrastan con los seis $(0.015)$ y cinco (0.008) comandados por Ruiz Massieu y Videgaray, respectivamente. A pesar del descenso de la actividad, sintomático del buen estado y la maduración de la relación fue que, durante el repliegue, se concretó la histórica visita de Estado de Raúl Castro a Mérida (noviembre de 2015) y el presidente mexicano ofreció

${ }^{27}$ Díaz Reynoso, op. cit., p. 53. 
un discurso durante las exequias de Fidel Castro (noviembre de 2016), honor concedido a pocos mandatarios.

Otro cambio de curso durante este ciclo de la diplomacia peñista fue la gradual normalización con Venezuela. La escalada de tensiones sintetizada en la expresión "cachorro del imperio" y el consecuente retiro de embajadores (noviembre de 2005), la denuncia venezolana al G3 (mayo de 2006), la campaña negativa de "Peligro para México" de Calderón (2006) y las expropiaciones de empresas mexicanas (20072010) distanciaron a los gobiernos durante poco más de un lustro. Si bien en noviembre de 2011, con la visita de trabajo del entonces canciller Nicolás Maduro, trató de relajarse la rispidez, no fue sino hasta la llegada del "nuevo PRI" que se abordó la situación desde un enfoque distinto.

La asistencia del presidente Peña Nieto al funeral de Hugo Chávez, en marzo de 2013, marcó el comienzo de una serie de cinco encuentros entre cancilleres que culminó con la celebración de la II Comisión Binacional Permanente (COBIPER) en noviembre de 2014, aplazada desde la década de los noventa. ${ }^{28}$ Empero, a diferencia de Cuba, el intento de normalización fracasó más tarde: la profunda crisis venezolana que arrancó en 2015, así como los cambios en el contexto interno de Estados Unidos y en la oEA culminaron con una nula interlocución (cero encuentros presidenciales, una reunión de cancilleres con Ruiz Massieu y tres con Videgaray y cero celebración de mecanismos binacionales), un franco distanciamiento (39.9\% del sexenio México no contó con embajador en Caracas) y nuevas tensiones entre ambos gobiernos por el Grupo de Lima y las declaraciones de Maduro al llamar "empleado de Donald Trump" y "cobarde" a EPN. ${ }^{29}$

28 Una prioridad era reactivar el marco institucional bilateral, pues la I reunión de la совіPER se había celebrado en abril de 1998. Véase: Víctor Hugo Morales Meléndez, "Una renovada presencia e influencia de México en América del Sur”, Revista Mexicana de Política Exterior, núm. 114 (septiembre-diciembre 2018), p. 71.

29 "Peña es 'un empleado maltratado por su jefe Trump': Maduro", Proceso, 3 de agosto de 2017. 


\section{REPLIEGUE: TORMENTA NACIONAL, NUBARRONES}

AL NORTE Y ONDA EXPANSIVA AL SUR

El ferrocarril del "nuevo PRI" se descarriló antes de llegar a la segunda estación del sexenio. El país que se imaginaba despertando de su letargo pasó a enfrentar los monstruos con los que nunca dejó de cohabitar. Al cierre de 2014, una serie de eventos trágicos (Tlatlaya y Ayotzinapa), casos ignominiosos de corrupción (la Casa Blanca) y retrocesos (incremento de la violencia y repunte de la pobreza) pincharon la burbuja gubernamental que pretendió encapsular los graves problemas del México del siglo XxI.

Con presión social y los ojos del mundo encima, el gobierno de Peña Nieto se esforzó por contener el daño en la imagen del país, reconociendo, aunque de manera matizada, la gravedad de la crisis de violencia, derechos humanos y corrupción, y estableciendo tres zonas económicas especiales. En lo que respecta a la política exterior, este ajuste llegó después de las elecciones intermedias, apagando el motor promocional de la actividad en Alyc. Sin embargo, la pérdida de dinamismo diplomático fue relativa, ya que la propia crisis interna de inseguridad y derechos humanos obligó a responder a cuestionamientos e intervenciones de la comunidad internacional, además de buscar acompañamientos externos para recuperar la credibilidad perdida. Parte de esta trama tuvo como escenario principal a ALyC y como actores protagónicos a los mecanismos regionales de derechos humanos y organizaciones sociales ${ }^{30}$ con arraigo latinoamericano.

El repliegue hacia la agenda interna, además de contener la crisis de legitimidad del gobierno, también tuvo como fin reacomodar al gabinete de cara a la elección presidencial

30 Destaca la intervención de la Comisión Interamericana de Derechos Humanos (CIDH) para crear el Grupo Interdisciplinario de Expertos Independientes (GIEI), con juristas y médicos de España y América Latina, para investigar la desaparición de los 43 estudiantes de la Escuela Rural de Ayotzinapa, con su secuela de desencuentros con las autoridades mexicanas y descalificaciones mutuas. 
de 2018. La llegada de Ruiz Massieu a la cancillería, representante de una familia política priista de cepa pura, junto con el reposicionamiento de Aurelio Nuño y del eventual candidato oficialista en las elecciones de 2018, José Antonio Meade, fueron movimientos internos que afectaron el nivel de atención y actividad de la política exterior en ALyc.

Por otra parte, durante el repliegue surgieron nubarrones en el frente norte que tensaron la relación con Estados Unidos por el temor de contagio transfronterizo de la espiral de violencia en México, la hollywoodense fuga del Chapo y el discurso antimexicano del entonces precandidato Donald Trump. En un inicio, el gobierno de Peña Nieto optó por poner el piloto automático y confiar en la continuidad demócrata en la Casa Blanca como antídoto a la mala imagen de México entre algunos sectores de aquel país. Posteriormente, ya en forma el fenómeno Trump (julio de 2016), surgieron profundas diferencias dentro del gabinete acerca de cómo enfrentar la situación, tendiendo la mano o plantándole cara al republicano. ${ }^{31}$ México terminó interviniendo impensada y erráticamente en las elecciones presidenciales al otorgarle al candidato republicano un espacio de proyección con la invitación a Los Pinos (agosto de 2016), lo que culminó con el distanciamiento definitivo de la administración de Obama y el hundimiento de la popularidad del ejecutivo mexicano. Al adoptar esta política pobremente analizada, mal instrumentada y sin apoyo interno, se desestimó la oportunidad de capitalizar la masa crítica solidaria ${ }^{32}$ que surgió en la región como instrumento de contrapeso narrativo y simbólico a las posiciones hostiles de Trump.

${ }^{31}$ El secretario de Hacienda promovió un acercamiento con Trump aprovechando sus vínculos con la familia, a lo que la canciller Ruiz Massieu se opuso rotundamente. El hombre fuerte del gabinete ganó la partida inclinando la balanza en favor del apaciguamiento, triunfo efímero que le costó el puesto.

32 Sobre estas muestras de solidaridad latinoamericana de todo el espectro político regional, véase: Hugo Morales Meléndez, op. cit., p. 77. 
Disminuida la proyección internacional del "nuevo PRI" e inoperante la diplomacia mexicana frente a Estados Unidos, durante la etapa de repliegue los principales mecanismos causales de la política exterior hacia ALyc estuvieron determinados por dinámicas inerciales, protocolarias y de arrastre, en respuesta a los procesos económicos, políticos y sociales que acontecían en la región.

México redujo el ímpetu sobre la AP, dejando que ésta siguiera su propia marcha sin perseguir iniciativas importantes, ${ }^{33}$ aunque es de destacar que la administración siguió utilizando la marca "Alianza del Pacífico" como herramienta de relaciones públicas y para engrosar la agenda bilateral con los más de 50 Estados observadores. También México se subió de manera inercial y sin estrategia propia a una serie de reuniones interregionales en el marco de la $\mathrm{AP}^{34}$ y al diálogo con el Mercosur, liderado por Chile y Brasil, con el acompañamiento del Banco Interamericano de Desarrollo (BID) y de la Comisión Económica para América Latina y el Caribe (CEPAL).

Otra dinámica inercial fue el comercio con Alyc. A pesar de los esfuerzos de promoción, los acuerdos comerciales y la construcción de encadenamientos productivos, los intercambios continuaron siendo poco importantes (cuadro 2) y altamente volátiles. En comparación con los gobiernos pa-

33 Durante la promoción, los mandatarios de la AP adoptaron cinco declaraciones (Santiago, Cali, Cartagena, Punta Mita y Caracas) y cinco iniciativas importantes como el fondo de cooperación, el protocolo adicional al acuerdo marco y el acuerdo de cooperación en materia de asistencia consular. En el repliegue se firmó una declaración (Puerto Varas) y cinco instrumentos, entre los que destacan el acuerdo de cooperación a través de una plataforma de consultas migratorias y la declaración conjunta con Canadá. Durante la contención se subscribieron dos declaraciones (Cali y Puerto Vallarta) y tres documentos, en especial, la declaración conjunta con el Mercosur y la visión estratégica de la AP 2030.

${ }^{34}$ En 2016 se realizaron reuniones con la Asociación de Naciones del Sudeste Asiático (ANSEA), el Foro de Cooperación Económica Asia-Pacífico (APEC) y el Mercosur. Secretaría de Relaciones Exteriores, Tercer Informe de Labores 2015-2016, México, SRE, p. 15. 
nistas, durante los cuales se registraron tasas económicas positivas en la región (gráfica 3), durante este sexenio, la mala situación económica regional por la caída de los precios de los commodities tuvo un efecto negativo en el comercio de México con la región, agudizándose durante el periodo de repliegue.

\section{Cuadro 2}

Comercio exterior de México con América Latina y el Caribe

\begin{tabular}{|c|c|c|c|c|c|c|c|c|c|c|}
\hline & \multicolumn{3}{|c|}{$\begin{array}{c}\text { Participación de ALyC } \\
\text { en el comercio exterior } \\
\text { de México (2017) }\end{array}$} & \multicolumn{3}{|c|}{$\begin{array}{l}\text { Participación de México } \\
\text { en el comercio exterior de } \\
\text { ALyC (2017)* }\end{array}$} & \multicolumn{2}{|c|}{$\begin{array}{c}\text { Tasa } \\
\text { promedio } \\
\text { anual }^{* *}\end{array}$} & \multicolumn{2}{|c|}{$\begin{array}{l}\text { Tasa de crecimiento } \\
\text { entre el } 1^{0} \text { y el } 5^{\circ} \\
\text { año de gobierno** }\end{array}$} \\
\hline & $\operatorname{Exp}$ & $\operatorname{Imp}$ & Total & $\operatorname{Exp}$ & $\operatorname{Imp}$ & Total & $\mathrm{FCH}$ & $E P N$ & $\mathrm{FCH}$ & $E P N$ \\
\hline ALyC & $5.2 \%$ & $3.1 \%$ & $4.2 \%$ & $2.3 \%$ & $3.7 \%$ & $3.0 \%$ & $11.1 \%$ & $-3.7 \%$ & $30.0 \%$ & $-17.9 \%$ \\
\hline Caribe & $0.4 \%$ & $0.1 \%$ & $0.2 \%$ & $1.8 \%$ & $3.1 \%$ & $2.6 \%$ & $13.7 \%$ & $-0.4 \%$ & $19.1 \%$ & $-13.0 \%$ \\
\hline $\begin{array}{l}\text { Centroa- } \\
\text { mérica }\end{array}$ & $1.5 \%$ & $0.5 \%$ & $1.0 \%$ & $3.7 \%$ & $7.1 \%$ & $5.8 \%$ & $15.5 \%$ & $-5.3 \%$ & $57.8 \%$ & $-26.3 \%$ \\
\hline Sudamérica & $3.4 \%$ & $2.6 \%$ & $3.0 \%$ & $2.1 \%$ & $3.2 \%$ & $2.6 \%$ & $9.8 \%$ & $-3.2 \%$ & $23.8 \%$ & $-15.2 \%$ \\
\hline $\begin{array}{r}\text { Alianza del } \\
\text { Pacífico }\end{array}$ & $1.6 \%$ & $0.9 \%$ & $1.2 \%$ & $2.5 \%$ & $4.3 \%$ & $3.4 \%$ & $14.9 \%$ & $-3.0 \%$ & $46.5 \%$ & $-11.5 \%$ \\
\hline
\end{tabular}

* Estimaciones.

** Por falta de datos de 2018, para efectos comparativos se contrastan los cinco primeros años de Felipe Calderón y Enrique Peña Nieto.

Fuente: elaboración propia con datos de omc y UN Comtrade.

Por otra parte, desafortunadamente los viajes presidenciales realizados y recibidos durante este tiempo carecieron de una dirección estratégica, por lo que se redujeron a simples actos protocolarios. Por ejemplo, se perdió la oportunidad de aprovechar el contexto poskirchnerista para impulsar la relación con Argentina durante la visita de Estado del presidente mexicano (julio de 2016). Ese mismo patrón tuvieron las visitas efectuadas por los mandatarios de Honduras (febrero), Paraguay (agosto) y Panamá (noviembre) en 2016. 
GrÁFICA 3

Comportamiento del comercio con ALyc (2001-2017)

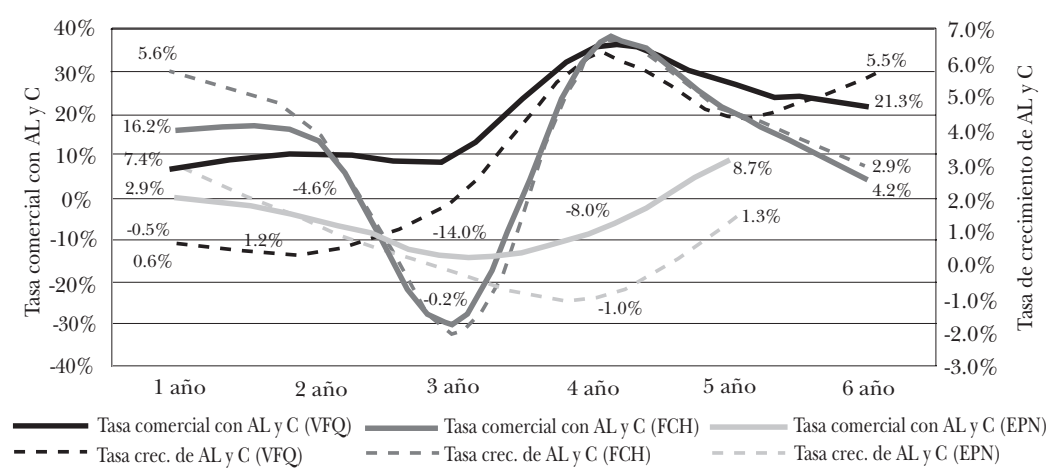

Fuente: elaboración propia con datos de la Secretaría de Economía.

Más lamentable fue el papel testimonial que desempeñó la diplomacia mexicana en el proceso de paz de Colombia. Si bien la relación personal de Peña Nieto y Santos posibilitó que México fuera invitado a las ceremonias de cese al fuego (junio de 2016) y de la firma de los acuerdos (septiembre de 2016), se desaprovechó la visita de Estado del Ejecutivo mexicano (octubre de 2016) para involucrarse de manera decidida en la etapa posconflicto, más allá del despliegue de 25 oficiales en la misión de verificación de la onU, el apoyo casi simbólico a la erradicación de minas antipersonales y su presencia tardía en las negociaciones con el Ejército de Liberación Nacional (ELN) que estaban en marcha.

Para el segundo semestre de 2015, los signos de turbulencia en la región eran ya alarmantes. A la inestabilidad política, con las interrupciones del mandato presidencial en Guatemala (septiembre de 2015) y Brasil (agosto de 2016), las alternancias electorales en diciembre de 2015 en Argentina (presidencial) y Venezuela (legislativa) y el rechazo mediante referéndum de los acuerdos de paz en Colombia (octubre de 2016), se sumaron el deterioro de las conquistas sociales al- 
canzadas en la primera década del siglo $\mathrm{xxI}^{35}$ y la contracción de la economía regional entre 2015 y 2016, particularmente en el Caribe y Sudamérica. ${ }^{36}$ Asimismo, en el Caribe, como consecuencia de la aceleración del cambio climático global, se registró un aumento en la frecuencia y magnitud de desastres naturales, con alto grado de destrucción en aquellos lugares con baja resiliencia (destacan los destrozos materiales ocasionados en esta etapa por los huracanes Joaquín, Earl y Matthew).

A este clima de deterioro social, decaimiento económico e inestabilidad política, habría que añadir los vacíos, parálisis y fragmentaciones registrados en el tablero multilateral. Más allá de la AP, y de la posterior utilidad que el canciller Videgaray quiso darle a la oEA, durante este sexenio se desestimó la utilidad de mecanismos regionales como la CELAC, al no dotarla de contenido y dirección, y rebajando su papel a la de un foro regional estéril para la diplomacia mexicana. Desde un inicio, la administración "tenía claro que la cELAC no podría constituirse en sustituto de la OEA", 37 pues se trataba de un rompecabezas aún por armar para la representación global de la región que contrastaba con el capital acumulado de la organización continental en el manejo de conflictos regionales. Así pues, el gobierno peñista continuó con la política de participación en la oEA que habían iniciado los gobiernos panistas con el impulso a la agenda de derechos humanos ${ }^{38}$

${ }^{35}$ Entre 2002 y 2014, poco más de 60 millones de personas en la región salieron de la pobreza, la población en pobreza extrema cayó de 11 a $8 \%$ y aquélla en situación de pobreza de 45 a 28\%. A partir de 2015 hay un repunte de indigencia y pobreza ( 10 y $30 \%$, respectivamente, en 2017). CEPAL, Panorama social de América Latina 2018, Santiago, 2019, 225 pp.

${ }^{36}$ Entre 2015 y 2016 la economía regional se contrajo -0.5 y $-1.0 \%$, pero la caída fue mayor en Sudamérica (-1.7 y -2.4\%, respectivamente) que en el Caribe (-0.5 y - $0.8 \%)$, en tanto que Centroamérica y México registraron tasas positivas del 3 y $2.5 \%$, respectivamente.

${ }^{37}$ Luis Alfonso de Alba, op. cit., p. 24.

${ }^{38} \mathrm{El}$ entonces representante mexicano en la OEA describe los esfuerzos por fortalecer el sistema regional de derechos humanos frente a los cuestionamientos de los países del Alba, ibid., p. 25. 
y el interés de capitalizar -en imagen, reputación, voz y votos-, sus históricas contribuciones financieras. ${ }^{39}$ Como parte de esta inercia, por primera vez desde la fundación de la oEA, México fue electo en la reunión de República Dominicana de 2016 como sede de la siguiente Asamblea General a celebrarse en 2017. ${ }^{40}$ En ese momento, el gobierno mexicano no anticipaba la espiral de desencuentros y tensiones que la crisis venezolana provocaría en esa ocasión, ni la polarización dentro del organismo, a pesar de que desde mediados de 2015 se presagiaban dificultades por el protagonismo del nuevo secretario general, Luis Almagro.

No obstante, los cataclismos que demandaban una política exterior activa en Alyc durante el repliegue, ésta fue más reactiva que propositiva y más errática e inconsistente que estratégica. En un contexto preelectoral, la canciller Ruiz Massieu privilegió una diplomacia de consumo interno que le diera visibilidad (con temas como los de género o la gastronomía mexicana), teniendo como resultado final un raquítico nivel de actividad latinoamericana, medido en términos de interlocución. A pesar de su importancia geoestratégica, con sus pares centroamericanos tan sólo tuvo 10 encuentros (en comparación con 25 y 30 de los cancilleres Meade y Videgaray, respectivamente) y 11 con los caribeños (28 y 16, equivalentemente), mientras que con los jefes diplomáticos sudamericanos la canciller sostuvo 18 reuniones (34 y 36 en la promoción y contención, respectivamente).

A pesar de la desatención de la región durante el repliegue, la diplomacia mexicana se vio arrastrada por situaciones de las que no pudo excusarse, como las crisis migratorias haitiana y cubana (2016) que generaron presiones en las fronteras centroamericanas y mexicanas. Miles de haitianos que habían emigrado a Brasil tras el terremoto de 2010, ante la

${ }^{39}$ Natalia Saltalamacchia, "¿Cómo atar al gigante? Seis décadas de México en la oeA", Pensamiento propio, vol. 19, núm. 39 (enero-junio de 2014), pp. 249-286.

${ }^{40}$ Secretaría de Relaciones Exteriores, Tercer Informe, p. 16. 
difícil situación económica del país carioca comenzaron a desplazarse hacia Estados Unidos en busca de oportunidades. De forma parecida, y derivado del deshielo de la relación Cuba-Estados Unidos y el inminente fin de la política de "pies secos, pies mojados", miles de cubanos salieron de la isla rumbo a Ecuador (con leyes migratorias laxas) para emprender desde ahí su traslado hacia el norte. Ambas situaciones obligaban a ejecutar una política exterior activa que concertara posiciones y acciones conjuntas para atender estos flujos. Empero, México respondió de manera contingente, aunque eficaz, y con un escaso diálogo con las demás partes involucradas. La excepción fue la buena interlocución con Costa Rica y Cuba, con acompañamiento de la oeA ante la incapacidad del Sistema de la Integración Centroamericana (SICA), para procesar concertadamente el tránsito de los migrantes cubanos varados en Centroamérica, tras el cierre de la frontera nicaragüense. ${ }^{41}$

Tras el batacazo electoral de la oposición venezolana en diciembre de 2015, a la penosa situación económica se sumó un deterioro progresivo de la democracia en ese país. Los ataques judiciales contra la Asamblea Nacional, la subsecuente represión de las marchas opositoras y el establecimiento de una Asamblea Constitucional oficialista de manera ilegal fueron el detonante de la crisis política y humanitaria más grave que haya vivido un país latinoamericano. En este contexto, la oposición venezolana buscó en forma activa el respaldo internacional, entre ellos México, como medida para contener los embates del oficialismo.

En este periodo, el déficit de liderazgos regionales impidió articular respuestas colectivas ante el desafío venezolano, por lo cual México se vio obligado a cambiar su posición inicial del sexenio y empezó a entablar contactos con la oposición venezolana, como ocurrió con la mediática visita de Lilian Tintori en febrero de 2016. Sin embargo, el enfoque fue reactivo y sin una visión estratégica fundamentada de conver-

${ }^{41}$ Daniel Villafuerte Solís, et al., op. cit., pp. 24-26. 
tir a nuestro país en un actor relevante en la solución de este problema.

De hecho, el trasfondo de este cambio obedecía primordialmente a una lógica de política interna. En un escenario de erosión de legitimidad del gobierno peñista y en la antesala del proceso electoral de 2018 con el resurgimiento de AMLO como figura opositora, a la cabeza de su nuevo partido Morena, el lucro político-electoral de "evitar el chavismo" fue la principal fuente de condena al régimen venezolano. Diferentes actores oficialistas, desde el presidente Peña Nieto hasta el líder del PRI, Enrique Ochoa, pasando por la propia canciller, utilizaron las críticas al régimen de Maduro como un instrumento vocal de proselitismo electoral.

\section{Contención: Tres tableros en movimiento}

En el último tercio del sexenio, a la superposición de crisis nacional y regional que encaraba el gobierno mexicano se sumó la ruptura del paradigma que guió la relación MéxicoEstados Unidos durante las últimas décadas. El triunfo de Donald Trump, en contra de la "sabiduría convencional", significó para México la instalación de facto de un gobierno abiertamente hostil en su frontera norte.

El cambio de enfoque radical respecto al comercio, el endurecimiento frente a la migración y el controvertido tema del muro erosionaron toda base sólida de encuentro entre ambos países. Esta nueva realidad desencadenó una serie de cambios en el interior del gobierno, donde la política exterior retomó su importancia de la mano del nuevo canciller Luis Videgaray, hombre fuerte del presidente con vínculos con la administración Trump.

Esta concatenación de factores redefinió el valor estratégico de ALyc para la política exterior del gobierno mexicano al configurarla como un instrumento diplomático defensivo para contener, contrapesar y apaciguar a su vecino del norte pero, al mismo tiempo, entrecruzando su funcionalidad con 
los intereses gubernamentales de apuntalar su imagen interna y contrarrestar el ascenso de AMLo en la campaña presidencial de 2018. Así se activaban los mecanismos estratégico e interno durante la contención.

Asimismo, el factor de arrastre se mantuvo encendido. Aunque de manera circunstancial, la política exterior continuó teniendo como eje rector la atención de crisis, vacíos, parálisis y polarizaciones regionales presentes desde el segundo semestre de 2015, y que no se redujeron en el último tramo del sexenio. En este periodo de contención, en un contexto de raquítica recuperación económica en la región, ${ }^{42}$ la diplomacia mexicana tuvo que afrontar nuevas turbulencias y cambios en ALyc: las crisis institucionales producto de la viciada elección presidencial en Honduras (noviembre de 2017) y la que derivó en la renuncia de Pedro Pablo Kuczynski a la presidencia peruana (de diciembre de 2017 a marzo de 2018); el inicio de la crisis política en Nicaragua (abril de 2018); la agudización venezolana por la reelección de Maduro (mayo de 2018); las alternancias de gobierno en Bahamas, Barbados, Chile, Colombia, Ecuador y Haití y los devastadores huracanes Irma, José y María en el Caribe (2017).

Para enero de 2017, el panorama era sumamente complejo por la conjunción de desequilibrios simultáneos en los tres tableros que definen la política exterior mexicana en ALyc, obligando a reiniciar los motores diplomáticos y acelerar la marcha durante este periodo de contención.

Históricamente la región ha servido de pie de apoyo a la política exterior mexicana en su vinculación con Estados Unidos, por la dinámica primordialmente triangular y secundaria de la relación México-Alyc. Sin embargo, esta utilidad fue relativamente pasiva en las dos etapas previas del sexenio peñista. El incremento en la plusvalía regional fue notoria en el periodo de contención, ya que el gobierno mexicano la definió como área prioritaria de diversificación comercial frente al inminente cierre de espacios en el mercado estadounidense

${ }^{42}$ CEPAL, op. cit ( $c f$. nota 15). 
por el repunte del nacionalismo. Por primera vez desde los años noventa, las elites gubernamentales comenzaron a percibir el tema de la diversificación económica como una tarea pendiente de carácter imperativo, más que opcional. Así pues, el catalizador primario de la diplomacia mexicana hacia la región fue la necesidad de impulsar negociaciones comerciales, a cargo de la Secretaría de Economía, en su búsqueda de mercados y proveedurías alternativas frente a las medidas proteccionistas de Trump.

Mediante tres líneas generales de acción, acopladas a la estrategia global de diversificación que anunció la administración de Peña Nieto en enero de 2017, se buscó dar respuesta al cambio de contexto en Norteamérica. En primer lugar, como área natural de articulación de consensos globales, Alyc sirvió de plataforma para construir un equilibrio suave a las posiciones proteccionistas estadounidenses entre los países de la región. Algo sintomático de esta política fue la celebración de la trilateral Argentina-Brasil-México (abril de 2017), en Buenos Aires, con el objetivo de acercar posiciones orientadas a la defensa del sistema multilateral de comercio en mecanismos como G20 y la omc. ${ }^{43}$

Un segundo vector de contención y contrapeso al "nuevo Estados Unidos" se accionó como consecuencia del retiro de la administración Trump del Acuerdo Transpacífico de Cooperación Económica (TPP, por sus siglas en inglés), en enero de 2017. Este hecho desencadenó reacciones entre los restantes signatarios. México, junto con sus socios de la AP, convocaron una reunión ministerial extraordinaria del mecanismo en Viña del Mar (marzo de 2017), con cuatro objetivos: acelerar el desarrollo de encadenamientos productivos al interior de la alianza; establecer la categoría de Estado Asociado para negociar acuerdos comerciales con terceros países; detonar el proceso de integración regional a través del acercamiento AP-MERCOSUR; y celebrar un diálogo de alto nivel con países

${ }^{43}$ Secretaría de Relaciones Exteriores, Quinto Informe de Labores 20162017, México, SRE, p. 25. 
de la región Asia Pacífico, lo que es considerado la piedra angular del Tratado Integral y Progresista de Asociación Transpacífico (СРTPP, por sus siglas en inglés), el cual sustituyó al TPP ya sin Estados Unidos.

Por tales motivos, la AP resultó ser un firme punto de partida para México al ampliar su red de mercados en Asia Pacífico, al mismo tiempo que dinamizaba sus vínculos comerciales con ALyc. Una de las consecuencias positivas que desató el efecto Trump fue el repensar la región como "factor de alivio" y un estímulo para avanzar en la integración latinoamericana. ${ }^{44}$ Así, las rígidas alianzas que gobernaron el primer quinquenio del siglo dieron paso a una inicial cooperación técnica entre AP-MERCOSUR, así como la celebración de su primera cumbre en Puerto Vallarta (julio de 2018). Lejos se quedó el acercamiento de resultados concretos y de gran impacto, pero en perspectiva histórica, su valor simbólico fue muy importante al visibilizar el enorme potencial de una posible convergencia.

Por último, el gobierno mexicano buscó comprar una póliza de seguro regional ante la amenaza estadounidense de cerrar su mercado a las exportaciones y, más importante aún, encontrar fuentes alternativas de suministro de las importaciones agrícolas como instrumento de presión sobre las bases electorales de Trump para que éstas intercedieran frente a su gobierno. Por tal razón, México aceleró las negociaciones comerciales que tenía en curso con Argentina y Brasil a fin de profundizar y modernizar sus Acuerdos de Complementación Económicas (ACE), y empezó a dar los primeros pasos para actualizar algunos capítulos del Tratado de Libre Comercio con Uruguay y mejorar su asociación económica con Ecuador y Paraguay.

Sin embargo, los términos alcanzados en la renegociación del tratado comercial con Estados Unidos terminaron

${ }^{44}$ Luz María de la Mora, Hacia dónde se dirige el régimen de comercio internacional y sus implicaciones para América Latina, México, CEPAL, Sede Subregional en México, mayo 2018, p. 10. 
por afectar negativamente los términos negociados con Argentina y Brasil, en especial por el cambio en las normas de origen pactadas en el T-MEC. Al final del sexenio, el frente de negociaciones comerciales con Latinoamérica estaba prácticamente congelado, ${ }^{45}$ resaltando una vez más el carácter secundario de la relación con Alyc. Pero también a consecuencia de los efectos disruptivos en la región, con la incertidumbre electoral y el fenómeno Bolsonaro en Brasil, ${ }^{46}$ y las dificultades económicas de la Argentina de Macri. ${ }^{47}$

Como se ha señalado previamente, si bien desde la segunda mitad del sexenio la diplomacia presidencial se redujo sustantivamente, la pinza de este renovado activismo mexicano en la región la cerró la labor del canciller Videgaray, al efectuar 82 encuentros con pares y 34 giras regionales. La frenética diplomacia del canciller tuvo como resultado un mejor y mayor acercamiento con aquellos países con los que se había tenido una reducida interacción previa, como Bahamas, Bolivia, Jamaica y Santa Lucía , pero también estableciendo un fluido diálogo con todos los países latinoamericanos (a excepción de Venezuela) y la mayor parte de los caribeños. Se aceleró el paso para dar continuidad "a la estrategia de lograr un acercamiento con todos los países de la región, más allá de las diferencias". ${ }^{48}$

${ }^{45}$ Después de ocho rondas de negociaciones, cinco de las cuales se llevaron a cabo entre 2016 y 2017, al calor de la amenaza de Trump, para finales de 2018 México y Brasil no habían logrado cerrar la modernización y ampliación del ACE 53.

${ }^{46}$ El triunfo de Jair Bolsonaro (octubre de 2018) marcó la ruptura del espectro político brasileño dominante desde 1994. La contracción económica en $2015(-3.5 \%)$ y $2016(-3.3 \%)$, el repunte del desempleo, la amplia corrupción que enredó a gran parte de la clase política y la espiral de violencia explican este giro.

${ }^{47}$ En 2018, la economía argentina se contrajo (-2.6\%, proyección CEPAL) tras la subida de las tasas de interés estadounidenses y la peor sequía en medio siglo. El gobierno de Macri se vio forzado a pedir dos rescates al Fondo Monetario Internacional (FMI) por $57 \mathrm{mmd}$, arriesgando su reelección en octubre de 2019.

${ }^{48}$ Secretaría de Relaciones Exteriores, Sexto Informe de Gobierno 20172018, México, SRE, 2018, p. 17. 
México no quiso explotar el respaldo de ALyc contra las acciones del nuevo gobierno estadounidense, para no afectar ni contaminar la renegociación en curso del TLCAN. Empero, el canciller Videgaray sí aprovechó la buena sintonía política resultante para formar consensos y apoyos en el tablero regional. También, a la luz del repliegue de los líderes que dominaron previamente el panorama latinoamericano y caribeño y la parálisis multilateral, así como las crecientes demandas regionales para que México asumiera un mayor protagonismo, la diplomacia mexicana buscó construir un "liderazgo compartido" para atender las turbulencias regionales, en particular, la crisis venezolana.

La magnitud de la crisis en Venezuela acaparó la atención de los países de ALyc, no solamente por su desfondo económico, ${ }^{49}$ sino por las repercusiones políticas, ${ }^{50}$ sociales ${ }^{51}$ y humanitarias ${ }^{52}$ para el conjunto regional. Esta intensa fuerza centrípeta sobre la política exterior mexicana ocupó un espacio muy importante durante este periodo de contención por tres motivos: atender y contener este fenómeno a

${ }^{49}$ En 2017, tras años de decrecimiento económico, el PIB venezolano era $42 \%$ menor al de 2013. Véase: Fondo Monetario Internacional, World Economic Outlook Databases (WEO), Washington, FMI, https://www.imf. org/external/pubs/ft/weo/2018/02/weodata/index.aspx (consulta del 10 de diciembre de 2018).

${ }^{50}$ En 2016 empezó la erosión del marco constitucional y de la institucionalidad democrática. En 2017, Freedom House pasó a considerar a Venezuela como un país "no libre". Véase: Freedom House, Freedom in the world, Nueva York, Freedom House, https://freedomhouse.org/report/ freedom-world/2017/venezuela (consulta del 10 de diciembre de 2018).

${ }^{51}$ Entre 2014 y 2017, la población por debajo de la línea de pobreza aumentó de 48 a 87\%. Véase: Universidad Católica Andrés Bello et al., Encuesta Nacional de Condiciones de Vida, Caracas, uCAB-usb-ucv, 2018.

${ }^{52}$ La crisis humanitaria desembocó en el mayor desplazamiento migratorio en Sudamérica. El Alto Comisionado de las Naciones Unidas para los Refugiados (ACNUR) y la Organización Mundial para la Migración (OIM) calculan que de 2014 a 2018, 3 millones de venezolanos (9\% de la población) salieron del país y, la mayoría (2.4 millones), se asentaron en ALyc. Véase: "El número de refugiados y migrantes de Venezuela alcanza los 3 millones", огм, 8 de noviembre, 2018. 
través de un liderazgo compartido; encadenar el tema Venezuela a la relación bilateral con Estados Unidos como instrumento de apaciguamiento; y visibilizar internamente la gran dimensión de la crisis y resaltar los posibles riesgos del populismo de izquierda con fines electorales.

$\mathrm{Al}$ arribar Videgaray a la cancillería mexicana, la diplomacia profesional anticipaba que tendría que participar ineludiblemente, pero que su atención podía entrecruzarse con los intereses particulares de México en relación con Estados Unidos y su agenda interna. Por tal motivo, se optó por la vía multilateral dentro de la coalición de países inclinados a imponer condenas y sanciones regionales al régimen de Maduro. En un primer tiempo, la oEA pareció ser el espacio idóneo para ejercer presión sobre el gobierno venezolano debido al protagonismo de su secretario general, Luis Almagro, y porque México sería la sede de la $47^{\mathrm{a}}$ Asamblea General en Cancún (junio de 2017). Sin embargo, la reunión terminó con un duro revés para la diplomacia mexicana al no alcanzar los votos necesarios para adoptar una resolución condenatoria. ${ }^{53}$

No obstante, este golpe en la reputación de México, Cancún fortaleció la cooperación y coordinación entre los países que veían con preocupación el deterioro de la situación en Venezuela. Ante la creciente polarización en la oeA, Perú y México decidieron convocar a un grupo ad hoc en Lima (agosto de 2017) a fin de endurecer la posición regional ante el régimen madurista. El Grupo de Lima ${ }^{54}$ personificó la diplo-

${ }^{53}$ México, junto con 13 países más (el G14, precursor del Grupo de Lima), convocaron a una reunión de Consultas de Ministros para analizar y tomar medidas ante el deterioro de la situación venezolana. Antes del inicio formal de la $47^{\mathrm{a}}$ Asamblea General, sometieron a votación una resolución que exigía la liberación de presos políticos, el cese de la violencia y la no celebración de elecciones para constituir la Asamblea Nacional Constituyente. México no alcanzó el umbral necesario de 23 votos. Véase: Javier Lafuente, "Así se gestó el fracaso de la condena a Venezuela en la cumbre de la OEA", El País, 25 de junio de 2017.

${ }^{54}$ A sus 12 miembros originales (Argentina, Brasil, Canadá, Chile, Colombia, Costa Rica, Guatemala, Honduras, México, Panamá, Paraguay 
macia de liderazgo compartido que se implementó durante este periodo como un mecanismo activo para adoptar condenas y sanciones financieras o llamar a consultas a sus embajadores en Caracas, pero también para aquellas medidas orientadas a mitigar la crisis humanitaria. Un estilo combativo poco frecuente en la historia de la diplomacia regional de México que llevó incluso a "no reconocer la legitimidad del proceso electoral" 55 mediante el que se reeligió Maduro.

México asumió cierto liderazgo en el tema con la invitación de la oposición venezolana, junto con Chile, al formar parte del Diálogo de Santo Domingo. ${ }^{56}$ Entre noviembre de 2017 y enero de 2018, el canciller Videgaray participó como mediador en tres rondas de negociación, hasta que se retiró en protesta por la convocatoria de la Asamblea Constituyente a elecciones presidenciales para mayo de 2018. ${ }^{57}$ Así pues, México se afirmó como interlocutor importante por el liderazgo regional desplegado, su diálogo directo con la oposición venezolana y su participación en este proceso de

y Perú), posteriormente se adhirieron Guyana y Santa Lucía. Entre agosto de 2017 y agosto de 2018, el grupo se reunió en ocho ocasiones.

55 Secretaría de Relaciones Exteriores, Comunicado de prensa, México, SRE, 21 de mayo de 2018.

${ }^{56}$ El gobierno venezolano convocó como mediadores a Bolivia, Nicaragua y San Vicente y las Granadinas, República Dominicana y el expresidente español, José Luis Rodríguez Zapatero, participaron como facilitadores. Entre el 30 de noviembre de 2017 y 6 de febrero de 2018, hubo cinco rondas de diálogo; el proceso se rompió tras la convocatoria del oficialismo a elecciones presidenciales, ignorando la demanda de la oposición en favor de elecciones equitativas con observación internacional.

57 El conflicto diplomático entre México y Venezuela se trasladó a otros campos de batalla. En 2017, el gobierno mexicano buscó la Secretaría General de la Asociación Latinoamericana de Integración (ALADI). Después de un intenso cabildeo, a principios de julio se contaba con votos suficientes para ganar, sin embargo, en respuesta a las sanciones financieras adoptadas por el gobierno mexicano el 28 de julio, Venezuela trató de impedir la votación ausentándose del Consejo de Ministros. Al final, el candidato mexicano, Alejandro de la Peña, ganó con nueve votos a favor pero tres países (Bolivia, Cuba y Ecuador) se deslindaron del proceso sin objetar la elección. 
negociación. Por tal motivo, Venezuela resultó ser un punto de cooperación sólido entre las administraciones mexicana y estadounidense, un elemento no menor si se considera el espiral de rispidez bilateral que caracterizó el inicio del periodo de Trump.

Apaciguar a Estados Unidos a través de la interlocución sobre el tema fue notorio y recurrente en las reuniones de cancilleres celebradas entre Videgaray y Rex Tillerson y, posteriormente, Mike Pompeo. De las diez reuniones bilaterales realizadas entre enero de 2017 y agosto de 2018, en cuatro transcendió ${ }^{58}$ que la crisis venezolana era un asunto de conversación, así como en la reunión de ministros de Relaciones Exteriores de América del Norte (febrero de 2018), en la que el jefe de la diplomacia mexicana dijo que los tres secretarios habían "confirmado nuestra preocupación y nuestra voluntad de seguir utilizando todos los instrumentos diplomáticos a nuestro alcance para contribuir al restablecimiento de la situación en Venezuela".59

Por último, en esta etapa de contención se registró un aumento notable en la frecuencia de pronunciamientos, unilaterales, bilaterales y multilaterales sobre la situación venezolana con respecto al periodo anterior (gráfica 4). En tan sólo tres años se pasó de 1.06 censuras al mes, durante el repliegue, a 2.55 mensuales, en la contención.

Si bien la crisis venezolana fue agudizándose en el transcurso de este tiempo, estaba claro que a las advertencias sobre los "peligros del chavismo" por parte de algunos actores de la administración peñista, ${ }^{60}$ se sumó una cancillería más vocal

${ }^{58}$ Secretaría de Relaciones Exteriores, Comunicados de Prensa, el 5 de abril de 2017, 30 de agosto de 2017, 2 de febrero de 2018 y 7 de mayo de 2018, México, SRE.

${ }^{59} \mathrm{Ibid}$., boletín del 2 de febrero de 2018.

${ }^{60}$ En una entrevista, el presidente Peña Nieto afirmó: "Han dicho que es muy parecido, que su fórmula es muy parecida y que les preocupa que, el día de mañana, ese discurso (de López Obrador) prospere; que el día de mañana, México, en vez de avanzar, como ha ocurrido en los último 25 años, se parezca a lo que hoy es Venezuela". Ciro Gómez Leyva, "Entrevista a Enrique Peña Nieto", Imagen Noticias, $1^{\circ}$ de septiembre, 2017. 
como instrumento mediático contra el principal adversario político en las encuestas hacia la elección presidencial de 2018.

\section{GrÁfICA 4}

Pronunciamientos mexicanos sobre Venezuela (agosto de 2015-agosto de 2018)

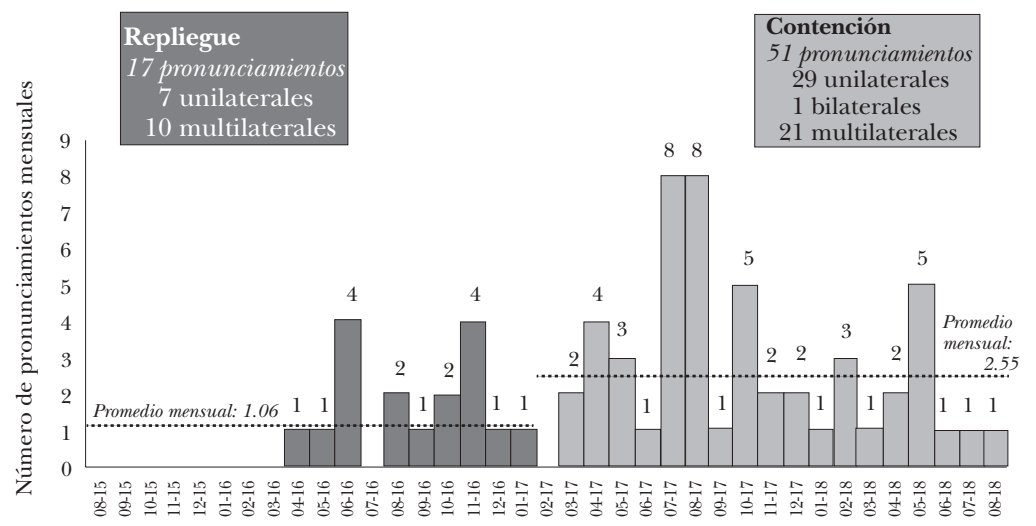

Fuente: elaboración propia con información de la Secretaría de Relaciones Exteriores.

\section{Conclusiones}

La política exterior es, por naturaleza, un campo de la política pública en el que convergen y se entrelazan varias pistas. Nuestro análisis acerca de la evolución de la política exterior de México hacia Alyc durante la administración de EPN, una de las áreas de mayor prioridad, visibilidad y actividad del gobierno peñista, muestra la manera en la que los responsables de tomar decisiones, en este caso el presidente y los tres cancilleres en turno, fueron ajustando y reformando sus acciones e iniciativas diplomáticas en función de las cambiantes condiciones del triple tablero internacional, regional y nacional.

Si bien esta constatación no resulta novedosa, la pequeña aportación del presente trabajo reside en las herramientas 
analíticas que se utilizaron para identificar y comparar, con cierto rigor, cómo y qué tanto cambió el nivel, el tipo de atención y la actividad diplomática en ALyc a lo largo de un gobierno que se fue enfrentando a alteraciones múltiples y simultáneas en las tres pistas. Dado que estas alteraciones no produjeron giros de timón ni reorientaciones mayores en la estrategia regional inicial -salvo quizá en el tema de Venezuela-, se trata de un caso de estudio esclarecedor sobre cómo operan los procesos de adaptación de la política exterior en contextos sistémicos, regionales y domésticos simultáneamente volátiles. Los ajustes y reformas ocurren a través de mecanismos de distinto tipo (estratégico, de proyección, de arrastre, internos e inerciales) que promueven o inhiben la atención y acción.

Las tres etapas claramente distinguibles en la política latinoamericana y caribeña de la administración de EPN respondieron a combinaciones distintas de los mecanismos mencionados. Se trata de momentos diferentes dentro de una misma estrategia de acercamiento pragmático con ALyc, encaminada a restablecer los espacios perdidos durante el ciclo de la "marea rosa" y apuntalar la proyección económica y global de México tras las reformas estructurales. La primera etapa, con la que abrió el sexenio y a la que llamamos "promoción", tuvo lugar durante la gestión del canciller Meade, fue la más activa, con mayor diplomacia presidencial y una franca orientación económica y de cooperación con énfasis en la AP, Centroamérica y el Caribe. Los mecanismos que la explican son sobre todo de proyección e internos.

El segundo periodo, bajo el mando de Claudia Ruiz Massieu, marcó una fase de repliegue detonada por mecanismos internos como la espiral de violencia, los escándalos de corrupción y el retroceso del oficialismo en las elecciones de medio término. La diplomacia presidencial en la región se mantuvo activa de manera inercial a consecuencia de compromisos asumidos previamente, al igual que las negociaciones económicas en el marco de la AP por el liderazgo de las burocracias profesionales. Fue evidente el descenso de 
atención y actividad diplomática regional de la canciller, sólo equilibrado por los mecanismos de arrastre, como el deterioro de situación en Venezuela, que llevó a un cambio de actitud hacia la oposición en ese país. La agenda se tornó menos económica y más política por las preocupaciones internacionales frente a la situación interna de derechos humanos.

La última etapa de contención bajo la conducción del hombre fuerte de la administración peñista, el canciller Videgaray, fue la más compleja porque en ella se encendió el mecanismo estratégico tras el giro radical de la política estadounidense con la administración Trump, junto con los motores de arrastre (Venezuela), internos (contienda electoral de 2018) e inerciales (Asamblea General de la oEA). Esta combinación de factores redefinió el valor estratégico de ALyc para la política exterior del gobierno mexicano, reactivando la atención y las acciones diplomáticas en la región. La diplomacia regional se convirtió en un instrumento defensivo de contención, contrapeso y apaciguamiento frente al vecino del norte, y en un espacio para apuntalar la alicaída imagen interna del gobierno y contrarrestar el ascenso de AMLO en la campaña presidencial de 2018. La diplomacia presidencial perdió vigor, mientras que la diplomacia del canciller se dinamizó; la actividad multilateral ganó peso y se centró más en la oEA que en la AP, en tanto que el énfasis subregional giró de Centroamérica y el Caribe hacia Sudamérica.

Bibliografía

Libros y artículos académicos

Amorim Neto, Octavio y Andrés Malamud, "What determines foreign policy in Latin America? Systemic versus domestic factors in Argentina, Brazil, and Mexico", Latin American Politics and Society, vol. 57, núm. 4 (2015), pp. 1-27. 
Cosío Villegas, Daniel, "Vida azarosa de la Doctrina Estrada", en Problemas de América, México, Clío/El Colegio Nacional, 1997, pp. 313-344.

Covarrubias, Ana, "La política de México hacia América Latina en el siglo XXI: ¿congruencia y legitimidad?”, Estudios Internacionales, 49 (2017), pp. 193-223.

Covarrubias, Ana "El reacomodo de México en una América Latina cambiante: de la euforia democrática a la introversión", Pensamiento propio, 21, núm. 44 (2016), pp. 325-326.

Covarrubias, Ana, “Containing Brazil: Mexico's response to the rise of Brazil”, Bulletin of Latin American Studies, 35, núm. 1 (2016), pp. 49-63.

Covarrubias, Ana, "Cuba, eeuu y América Latina”, Análisis Ribei, núm. 2 (enero de 2016), pp. 1-8, http:/ /www.ribei.org

De Alba Góngora, Luis Alfonso, "La política exterior de México hacia América Latina y el Caribe 2012-2018, logros y prospectiva", Revista Mexicana de Política Exterior, núm. 114 (2018), pp. 9-33.

De la Mora, Luz María, Hacia dónde se dirige el régimen de comercio internacional y sus implicaciones para América Latina, México, CEPAL, Sede Subregional en México, mayo 2018, 134 pp.

Díaz Reynoso, Miguel, "Política exterior de México hacia Centroamérica y el Caribe", Revista Mexicana de Política Exterior, septiembre-diciembre de 2018, núm. 114, pp. 35-61.

GÁmez, Alba E., "Fuentes de cambio en política exterior. Una revisión de los modelos de política exterior para los países en desarrollo", Afers Internacionals, núm. 69 (2005), pp. 127-151.

Gardini, Gianluca y Paul LAmbert, Latin American foreign policies: between ideology and pragmatism, Londres, Palgrave Macmillan, 2011, 272 pp.

GiacAlone, Rita, "Latin American foreign policy analysis: external influences and internal circumstances", Foreign Policy Analysis, vol. 8, núm. 4 (2012), pp. 335-354.

Gustavsson, Jakob, "How should we study foreign policy change?”, Cooperation and Conflict, vol. 34, núm. 1 (1999), pp. 73-95.

Hermann, Charles, "Changing course: when governments choose to redirect foreign policy", International Studies Quarterly, vol. 34, núm. 1 (1990), pp. 3-21. 
LASAGNA, Marcelo, "Cambio institucional y política exterior: un modelo explicativo", Afers Internacionals, núm. 32 (1996), pp. $45-64$.

LASAGNA, "Las determinantes internas de la política exterior. Un tema descuidado en la teoría de la política exterior", Estudios Internacionales, núm. 111 (1995), pp. 387-409.

Malamud, Andrés, "Presidentialist decision making in Latin American foreign policy: examples from regional integration processes", en Jorge Domínguez y Ana Covarrubias (eds.), Routledge Handbook of Latin America in the World, Londres, Routledge, 2014, pp. 112-23.

Merke, Federico y Diego Reynoso, "Dimensiones de política exterior en América Latina según juicios de expertos”, Estudios Internacionales, 185 (2016), pp. 107-131.

Merke, Federico, Diego Reynoso y Luis Schenoni, "Foreign policy change in Latin America: exploring a middle-range concept", Latin American Research Review, 2020, (en prensa), pp. 1-33.

Morales Meléndez, Víctor Hugo, "Una renovada presencia e influencia de México en América del Sur", Revista Mexicana de Política Exterior, núm. 114 (septiembre-diciembre de 2018), pp. 63-83.

O’NeIl, Shannon K., "Mexico Makes It. A Transformed society, economy, society, government”, Foreign Affairs, 92(2013), núm. 2, pp. 52-63.

Pastrana, Eduardo, La Alianza del Pacífico: de cara a los proyectos regionales y las transformaciones globales, México, Konrad Adenauer Stiftung/Gedisa/Pontificia Universidad Javeriana, 2016, 74 pp.

Saltalamacchia, Natalia, "The Mexican Agenda in Latin America: The Pacific Alliance”, CRIES, Anuario de la integración regional de América Latina y el gran Caribe, núm. 10 (2010), pp. 145-159.

Saltalamacchia, Natalia, “¿Cómo atar al gigante? Seis décadas de México en la oeA”, Pensamiento Propio, vol. 19, núm. 39 (2014), pp. 249-286.

Scartascini Carlos, Cesi Cruz y Philip Keefer, The database of political institutions 2017 (DPI2017), Washington, Banco Interamericano de Desarrollo, febrero de 2018. 
Villafuerte Solís, Daniel y María del Carmen García Aguilar, "De la crisis de los niños migrantes a la crisis de la migración cubana: intereses geopolíticos y expresiones sociales de la crisis del sistema migratorio México-Estados Unidos-Centroamérica entre 2014-2015”, Boletín de Antropología, vol. 31, núm. 52 (2016), pp. 15-33.

Documentos oficiales y bases de datos

Caribbean Elections, Election Centre (sitio de internet), última modificación, diciembre 2018, http:/ / www.caribbeanelections. com/elections/default.asp

Comisión Económica para América Latina y el Caribe (CEPAL), Estudio económico de América Latina y el Caribe 2018, Santiago de Chile, 2018, 248 pp.

Comisión Económica para América Latina y el Caribe (CEPAL), Panorama Social de América Latina 2018, Santiago de Chile, 2017, 225 pp.

Fondo Monetario Internacional, World Economic Outlook Databases (WEO), Washington, FMI, https://www.imf.org/exter$\mathrm{nal} / \mathrm{pubs} / \mathrm{ft} / \mathrm{weo} / 2018 / 02 /$ weodata/index.aspx

Freedom House, Freedom in the world, Nueva York, Freedom House, https://freedomhouse.org/report/freedom-world/2017/venezuela

Gobierno de la República, Plan Nacional de Desarrollo, 2013-2018, México, 2013.

Secretaría de Economía, Comercio exterior. Información estadística y arancelaria, México, SE, https://www.gob.mx/se/acciones-y-pro gramas/comercio-exterior-informacion-estadistica-y-arancelaria

Secretaría de Relaciones Exteriores, Programa Sectorial de Relaciones Exteriores 2013-2018, México, sRE, 2013, https://sre.gob.mx/ images/stories/marconormtivodoc/dof131213-p.pdf

Secretaría de Relaciones Exteriores, Primer Informe de Labores 20122013, México, SRE, 2013. 
Secretaría de Relaciones Exteriores, Segundo Informe de Labores 2013-2014, México, sRe, 2014.

Secretaría de Relaciones Exteriores, Tercer Informe de Labores 20142015, México, SRE, 2015.

Secretaría de Relaciones Exteriores, Cuarto Informe de Labores 20152016, México, SRE, 2016.

Secretaría de Relaciones Exteriores, Quinto Informe de Labores 20162017, México, SRE, 2017.

Secretaría de Relaciones Exteriores, Sexto Informe de Labores 20172018, México, SRE, 2018.

Secretaría de Relaciones Exteriores, Sala de Prensa, México, sRe, $1^{\circ}$ de diciembre de 2012 a 31 de agosto de 2018.

Organización Mundial de Comercio, WTO Statistics Database (base de datos en línea), Ginebra, omc, http://stat.wto.org/Home/ WSDBHome.aspx

Organización de las Naciones Unidas, UN Comtrade Database (base de datos en línea), Nueva York, onu, https://comtrade. un.org

Organización Internacional para la Migración, "El número de refugiados y migrantes de Venezuela alcanza los 3 millones", огм, 8 de noviembre de 2018.

Universidad Católica Andrés Bello, et al., Encuesta Nacional de Condiciones de Vida, Caracas, ucAB-usb-ucv, 2018.

\section{Prensa}

Crowley, Michael, "The committee to save Mexico", Time, 24 de febrero de 2014.

Gómez Leyva, Ciro, "Entrevista a Enrique Peña Nieto", Imagen Noticias, $1^{\circ}$ de septiembre de 2017.

Proceso, "Peña es «un empleado maltratado por su jefe Trump»: Maduro", Proceso, 3 de agosto de 2017.

"Mexico's Moment", The Economist, 21 de noviembre de 2012. "The rise of Mexico", The Economist, 24 de noviembre de 2012. 